\title{
Nucleation of $\mathrm{SiO}_{2}-\mathrm{CaO}-\mathrm{Al}_{2} \mathrm{O}_{3}$ Slag in Oxidative Ladle Refining of Metallurgical Grade Silicon
}

\author{
ERLEND L. BJØRNSTAD and GABRIELLA TRANELL
}

Oxidative ladle refining (OLR) is the most used refining method in industrial production of metallurgical grade silicon. OLR is performed by purging the liquid alloy with oxygen-enhanced air at $1823 \mathrm{~K}$ to $1873 \mathrm{~K}$, reacting with silicon and the primary slag forming impurities to a $\mathrm{SiO}_{2}-\mathrm{CaO}-\mathrm{Al}_{2} \mathrm{O}_{3}$ slag. To further increase our capability to control this process, it is paramount to understand how the slag nucleates and forms, and represent it such that it is useful for predicting and controlling the process behavior. This work aims to formulate a comprehensive theoretical description of slag nucleation and formation at nano/microscale using classical macroscale thermodynamics, bridging these spatial regimes. To achieve this, the work argues that silica's liquid structure allows its nuclei to exhibit "well defined" surfaces. Furthermore, silica is predicted to be highly surface active, so if its concentration is high while the slag nucleus is small, the $\mathrm{SiO}_{2}-\mathrm{CaO}-\mathrm{Al}_{2} \mathrm{O}_{3}$ slag should retain silica's surface properties. An experiment confirmed the surface active nature of silica in the $\mathrm{SiO}_{2}-\mathrm{CaO}-\mathrm{Al}_{2} \mathrm{O}_{3}$ system. It was also shown that increasing the slag's calcia concentration has a greater effect on the interfacial tension between the molten slag and liquid alloy than alumina, confirming industrial observations of the coupling between refining rate and relative alloy/slag composition.

https://doi.org/10.1007/s11663-021-02132-7

(C) The Author(s) 2021

\section{INTRODUCTION}

Metallurgical grade silicon (MG-Si) sees widespread use as a raw material or additive in many processes and products, such as silicones and aluminum alloys. It is also a precursor for photovoltaic and electronic grade silicon. MG-Si is typically produced by carbothermally reducing quartz in a submerged arc furnace (SAF). Further refining is then performed to customer specification. While any given plants refining scheme might differ, it typically includes oxidative ladle refining (OLR), a process through which the continuously tapped alloy is purged with an air-oxygen mixture. OLR is primarily used to reduce the content of $\mathrm{Ca}$ and $\mathrm{Al}$, which enter the process as part of the raw materials. A typical ladle contains over 7 tonnes of molten silicon when full, with a height of 2 to $2.7 \mathrm{~m}$ and top width of 1.5 to $1.8 \mathrm{~m}$, as seen in Figure 1. Impurity concentrations of $\mathrm{Al}$ and $\mathrm{Ca}$ in the melt tapped into the ladle lie typically between 0.5 and 2 wt pet, and is refined to approximately 0.01 to 0.5 [wt pet $\mathrm{Ca}$ ] and 0.1 to 1.2

ERLEND L. BJORNSTAD AND GABRIELLA TRANELL are with the Department of Materials Science and Engineering, Norwegian University of Science and Technology, Bergbygget E-133, Alfred Getz vei 2, IMA, NTNU, N-7491 Trondheim, Norway. Contact e-mail: erlend.1.bjornstad@ntnu.no

Manuscript submitted September 18, 2020; February 12, 2021.

Article published online April 9, 2021 [wt pet Al] $]^{*}$, depending on which silicon alloy is being

*Product data sheets accessed 06.05.20 from suppliers: Elkem(Silicon 99, SiLLOY 130/170), HOSHINE(Silicon Metal(multiple alloys)), and BAIDAO(Silicon Metal(multiple alloys)).

produced. The process as a whole takes between 1 and 2 hours, where further gas purging may continue as necessary to reach the desired impurity composition, after tapping ends. Temperatures typically range from $1500{ }^{\circ} \mathrm{C}$ to $1700{ }^{\circ} \mathrm{C}$, where the desired process temperature lies between $1500{ }^{\circ} \mathrm{C}$ and $1600{ }^{\circ} \mathrm{C}$. Impurities are transferred to a slag phase, created through reactions between the gas and melt. As the bubbles ascend, [Si] ( $\mathrm{Si}$ in the melt phase) reacts with $\left\{\mathrm{O}_{2}\right\}\left(\mathrm{O}_{2}\right.$ in the gas phase) to form $\left(\mathrm{SiO}_{2}\right)\left(\mathrm{SiO}_{2}\right.$ in the slag phase $)$ and $\{\mathrm{SiO}\}$ through equilibrium reactions 2 and 1 . Through reaction $2,\left(\mathrm{SiO}_{2}\right)$ nucleates on the bubble surface, initiating slag formation. While the nucleus grows, $\left(\mathrm{SiO}_{2}\right)$ will react with the primary slag forming impurities $[\mathrm{Al}]$ and $[\mathrm{Ca}]$, resulting in a predominantly $\mathrm{SiO}_{2}-\mathrm{CaO}-\mathrm{Al}_{2} \mathrm{O}_{3}$ slag droplet. The relevant reactions are assumed to be as follows:

1. $2[\mathrm{Si}]+\left\{\mathrm{O}_{2}\right\}=2\{\mathrm{SiO}\}$

2. $[\mathrm{Si}]+\left\{\mathrm{O}_{2}\right\}=\left(\mathrm{SiO}_{2}\right)$

3. $2[\mathrm{Ca}]+\left(\mathrm{SiO}_{2}\right)=2(\mathrm{CaO})+[\mathrm{Si}]$

4. $4[\mathrm{Al}]+3\left(\mathrm{SiO}_{2}\right)=2\left(\mathrm{Al}_{2} \mathrm{O}_{3}\right)+3[\mathrm{Si}]$

5. $2[\mathrm{Al}]+3(\mathrm{CaO})=\left(\mathrm{Al}_{2} \mathrm{O}_{3}\right)+3[\mathrm{Ca}]$ 


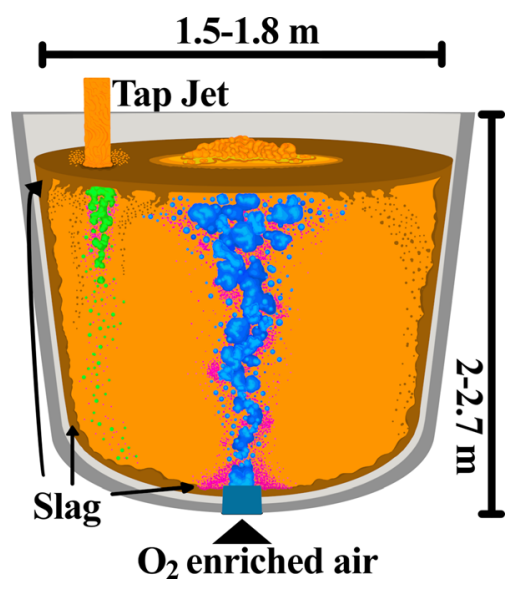

Fig. 1-Ladle refining system including the falling jet. Bubbles of entrapped air are displayed in green while the central bubble column is colored in blue. Slag leaving the bubbles is here displayed in purple, while the settled slag is in brown.

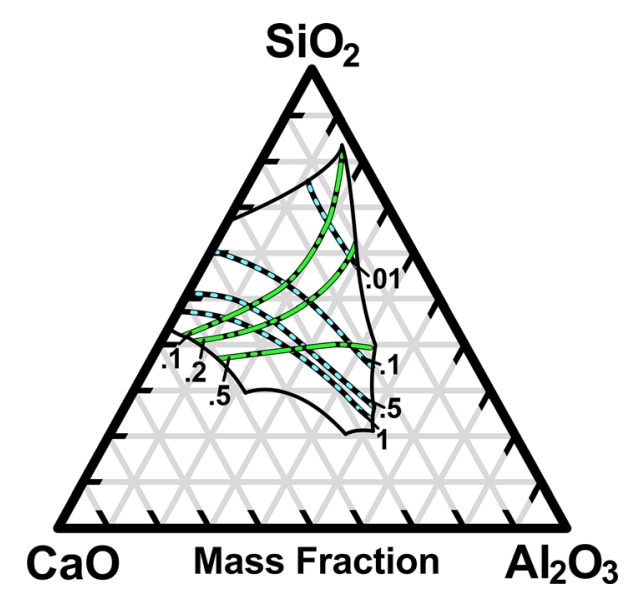

Fig. 2-How the equilibrium concentration of $\mathrm{Ca}(\mathrm{Blue})$ and $\mathrm{Al}(\mathrm{Red})$ (in wt pct) dissolved in liquid $\mathrm{Si}$ changes when in contact with different $\mathrm{SiO}_{2}-\mathrm{CaO}-\mathrm{Al}_{2} \mathrm{O}_{3}$ slags at $1823 \mathrm{~K}$. Calculated from Sigworth $^{[2]}$

The slag will still contain small concentrations of other oxide-forming impurities, such as $\mathrm{Ba}$, rare-earth elements, $\mathrm{Mg}$, etc., ${ }^{[1}{ }^{\text {but }}$ as minor components, they are not considered further in this work. To provide an idea of how the two primary slag forming impurities act with changing slag composition, Figure 2 summarized by Sigworth, ${ }^{[2]}$ shows how the equilibrium concentration of the impurities dissolved in liquid silicon changes with the slag composition.

At a certain point the droplet detaches from the ascending bubble, allowing coalescence with other droplets and further reactions with the melt. The slag droplet's path through the melt is determined by its perceived flow field and physical properties/composition, where the slag eventually settles at the ladle floor, walls, or as a floating top slag. While widely used, there are still many aspects of OLR in MG-Si production which are not well described in the literature. Schei et $a l .^{[3]}$ compiled much of the literature prior to 1998 , providing an overview of both system thermodynamics
Table I. System Parameters from Olsen et al. ${ }^{[4]}$

\begin{tabular}{lcccc}
\hline$X_{\left\{O_{2}\right\}, 0}$ & $X_{\left\{N_{2}\right\}, 0}$ & $T[K]$ & $\bar{d}_{b, 0}[m]$ & $H[m]$ \\
\hline 0.5 & 0.5 & 1900 & 0.01 & 0.69 \\
\hline
\end{tabular}

and some important slag properties. Important aspects of slag forming kinetics on the gas bubbles however, were not described. Olsen et al. ${ }^{[4]}$ and Ashrafian et al. ${ }^{[5]}$ later attempted to describe and model different aspects of the OLR process. While promising, the modeling work suffered from a lack of open experimental data in certain key areas. Kero et al. ${ }^{[1]}$ later provided data from an industrial refining campaign, where samples were taken in different ladles during the refining process.

The main piece of information currently missing for OLR pertain to the reaction kinetics between the gas, melt, and slag, and how the slag nucleates and grows on the bubble surface.

Hence, the current work aims to give a cohesive theoretical description of nucleation, species interaction, and slag behavior, supported by experimental work. Collectively, the work forms the basis of a new model framework for the OLR process, starting with the reactions on each individual gas bubble.

\section{THEORETICAL FRAMEWORK: NUCLE- ATION AND SLAG FORMATION}

As a start, it is useful to determine the maximum amount of slag that can be generated by a single gas bubble. This provides an upper bound, when looking at the size domains relevant for slag nucleation and initial growth. A possible method of handling the scaling issues relevant to transitioning between different size domains, from nano- to macroscale, is subsequently presented.

\section{A. Slag Generated on Each Bubble}

Olsen et al. ${ }^{[4]}$ modeled industrial refining of a 2 tonne ladle, using typical industrial parameters. They estimated a Sauter mean bubble diameter, using a model from Calderbank, ${ }^{[6]}$ between 7 and $10 \mathrm{~mm}$, with a gas flow rate of $45 \mathrm{Nm}^{3} / \mathrm{h} .{ }^{[4]}$ Table I lists some of the model parameters used in the study, together with the bubble diameter used in further calculations.

Here $X_{\left\{O_{2}\right\}, 0}, X_{\left\{N_{2}\right\}, 0}$ are the initial mole fractions of $\left\{\mathrm{O}_{2}\right\}$ and $\left\{\mathrm{N}_{2}\right\}$ in the purge gas, $T[K]$ is the melt temperature, and $\bar{d}_{b, 0}[m]$ is the initial Sauter mean bubble diameter. $H[m]$ is the melt height over the plug. Assuming an ideal gas, the initial amount of gas molecules in a gas bubble can be expressed as:

$$
n_{g, 0}=\frac{V_{b} P_{b}}{R T}[\mathrm{~mol}]
$$

where $V_{b}\left[\mathrm{~m}^{3}\right]$ is the initial bubble volume of one bubble, and $R[J / m o l K]$ is the ideal gas constant. $P_{b}$ is the pressure inside a bubble, which Olsen et al. assume 
equal to the atmospheric pressure. $\left\{\mathrm{O}_{2}\right\}$ reacts to form $\left(\mathrm{SiO}_{2}\right)$ and/or $\{\mathrm{SiO}\}$, where the amount of each species in moles, $n_{\{\mathrm{SiO}\}}$ and $n_{\left(\mathrm{SiO}_{2}\right)}[\mathrm{mol}]$, can be calculated as a function of the initial oxygen molar fraction in the gas bubbles, here assumed to be equal to that in the purge gas $X_{\left\{O_{2}\right\}, 0 \cdot}{ }^{[7]}$

$$
n_{\{\mathrm{SiO}\}}=\left(1-X_{\left\{\mathrm{O}_{2}\right\}, 0}\right) n_{g, 0} \frac{p_{\{\mathrm{SiO}\}}}{P_{b}-p_{\{\mathrm{SiO}\}}}
$$

where $p_{\{\mathrm{SiO}\}}$, using thermodynamic data from the FACT oxide database, ${ }^{[7]}$ can be expressed as

$$
\begin{gathered}
p_{\{\mathrm{SiO}\}} \approx \frac{n_{\{\mathrm{SiO}\}}}{n_{\{\mathrm{SiO}\}}+n_{\left\{N_{2}\right\}}+n_{\left\{O_{2}\right\}}} P_{b} \\
=\left(\frac{\exp \left(11.13+\frac{39464}{T}\right)}{\exp \left(-23.66+\frac{113623}{T}\right)}\right)^{\frac{1}{2}} P_{b} \quad[P a]
\end{gathered}
$$

If one assumes that all oxygen in the gas bubble forms $\{\mathrm{SiO}\}$ and $\left(\mathrm{SiO}_{2}\right)$ then:

$$
n_{\left(\mathrm{SiO}_{2}\right)}=n_{g, 0} X_{\left\{\mathrm{O}_{2}\right\}, 0}-\frac{1}{2} n_{\{\mathrm{SiO}\}}
$$

Combined, these allow the maximum amount of $\left(\mathrm{SiO}_{2}\right)$ produced by a single bubble to be calculated, assuming spherical bubbles. Using $\rho_{[\mathrm{Si}]} \approx 2500 \mathrm{~kg} / \mathrm{m}^{3[8]}$ and $\rho_{\left(\mathrm{SiO}_{2}\right)} \approx 2212 \mathrm{~kg} / \mathrm{m}^{3[4]}$ at $1900 \mathrm{~K}$, together with parameters from Table I, gives $m_{\left(\mathrm{SiO}_{2}\right)}^{\text {tot }} \approx 0.11 \mathrm{mg}$, which corresponds to a sphere with diameter $d_{\left(\mathrm{SiO}_{2}\right)}^{\text {tot }} \approx 0.46 \mathrm{~mm}$. It should also be noted, that as the slag composition changes so will its density. Interactions between slag and dissolved [Ca] and [Al] will lead to an increase in both (wt pct $\mathrm{CaO}$ ) and (wt pct $\mathrm{Al}_{2} \mathrm{O}_{3}$ ), which in turn will result in a higher density, thus decreasing the diameter. This means that a slag consisting of pure $\mathrm{SiO}_{2}$ will always provide the largest diameter possible.

For all molten $\mathrm{SiO}_{2}-\mathrm{CaO}-\mathrm{Al}_{2} \mathrm{O}_{3}$ slag compositions at $1823 \mathrm{~K}\left(1550^{\circ} \mathrm{C}\right)$, it can be shown that they will not change the earlier diameter of $\approx 0.46 \mathrm{~mm}$, by more than $0.05 \mathrm{~mm}$. While this represents a size given thermodynamic equilibrium, reaction kinetics and/or flow might affect the droplet size. Still, it provides a useful insight, and shows most notably that the maximum amount of slag one bubble can produce is small compared to the bubble itself, as seen in Figure 3.

It is important to note that $m_{\left(\mathrm{SiO}_{2}\right)}^{\text {tot }}$ is the maximum mass of $\left(\mathrm{SiO}_{2}\right)$ over all slag droplets an individual bubble can produce over its ascent. Thus, it seems reasonable to assume that each individual slag droplet is smaller than this value, most probably by orders of magnitude. This corresponds with analytical observations from the industry, where some of the sampling deviation is attributed to the presence of imperceptible micro-slag droplets in the metal. However, this has not been documented in any scientific publications.

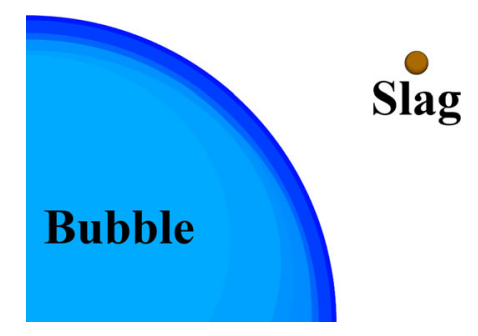

Fig. 3-Size comparison between a bubble and a slag droplet consisting of the total amount of $\mathrm{SiO}_{2}$ which can be produced by said bubble, using parameters from Table I.

An important note about the slag droplet size estimation is that changing process parameters, within reasonable boundaries, does not have a great impact the size regime. Adding hydrostatic pressure, changing the temperature $T \pm 100 \mathrm{~K} /{ }^{\circ} \mathrm{C}$, and/or assuming no production and back-filling of the bubbles with $\mathrm{SiO}\left(n_{\{\mathrm{SiO}\}}=0\right)$, the total slag droplet diameter will not change significantly. The effect of these changes will result in a change in droplet diameter $\Delta d_{\left(\mathrm{SiO}_{2}\right)}^{t o t}<0.04 \mathrm{~mm}$. Using different literature values for the density of molten silicon $\rho_{[\mathrm{Si}]}$ or for silica $\rho_{\left(\mathrm{SiO}_{2}\right)}$ does not change the size markedly either. Increasing the initial molar fraction of oxygen in the bubbles $X_{\left\{O_{2}\right\}, 0} \pm 0.2$ and the bubble size $\bar{d}_{b, 0} \pm 5 \mathrm{~mm}$ produce more significant changes, but the total slag droplet diameter is still within $\Delta d_{\left(\mathrm{SiO}_{2}\right)}^{\text {tot }}<0.5 \mathrm{~mm}$.

\section{B. Slag Nucleation}

The lower spatial boundary considered relevant to slag formation in OLR is assumed to be the slag's initial nucleus size. This size represents the initial condition for nuclei growth, as the system must be able to accommodate oxide nuclei of this size before the slag phase can form and subsequently grow. In this work only heterogeneous nucleation will be covered, as it is assumed that the slag forms on the gas bubble itself. The initial nucleus size is traditionally associated with the nanoscale, where many of the models and assumptions used at the micro/macro domain start to falter. An important aspect for such a model is where one phase ends and a new phase begins, i.e., a surface. Gibbs 9 and 10 divides two phases by placing a dividing surface/plane, separating the phases. This plane is a mathematical construct which cleanly separates each phase into uniquely distinguishable volumes without a gradual transition between the phases, allowing each surface to be clearly defined. Thermodynamic properties like surface tension, phase volume, surface area, etc. are properties of this plane, as these are all properties defined by the surface. Separating phases as described above is called the cluster approach (CA). This approach works well in systems where the surface region represents only a small part of the phase as a whole, but is not necessarily applicable for smaller systems where the surface region will represent a significant portion of the phase. In reality the surface can be viewed as a continuous change in a phase's respective particle density, as it continuously 


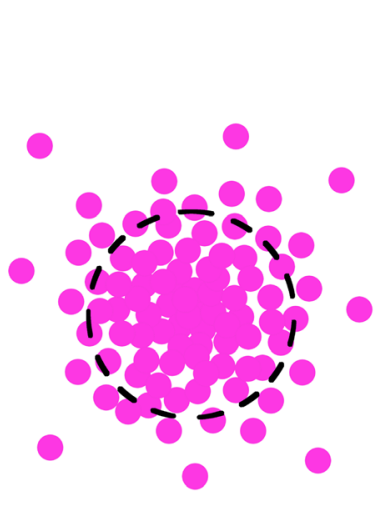

(a)

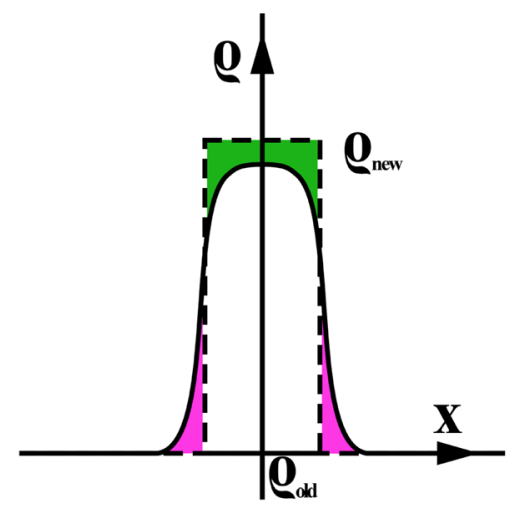

(b)

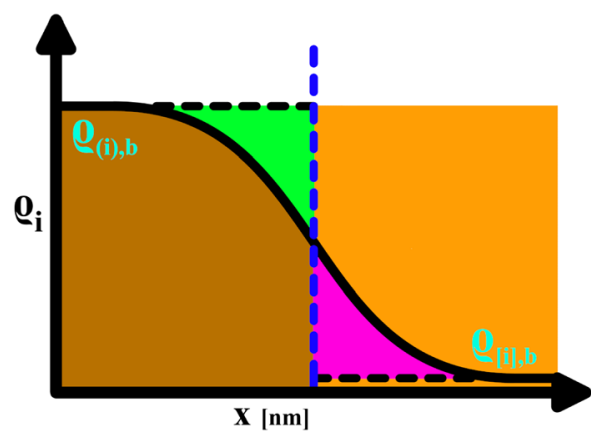

(c)

Fig. 4 - Schematic descriptions of two approaches to define a surface. (a) The cluster approach. Particles shown in pink and the phase's surface is shown by the dotted line. (b) Density functional approach. The black line $(\varrho(x))$ is the particle density function of a given species as one moves from one phase to the other. The pink area represent the concentration excluded by the cluster approach (The particles outside of the dotted line in a), and the green area represents the additional concentration added to the cluster to compensate for this. (c) Particle density of a species $i$ changes as one passes from the bulk of the slag in brown to the melt in orange. The dotted line indicates the equimolar dividing surface.

changes from the bulk density of the first phase to the bulk density of the second. This is called the density functional approach (DFA), and gives a more accurate representation of the surface than CA. Even though phase boundaries can be defined in multiple other ways, one finds that CA and DFA are the ones primarily used ${ }^{[11]}$ A more comprehensive description of DFA can be found in the literature (Kalikmanov ${ }^{[12]}$, Kashchiev $\left.^{[11]}\right)$.

Figure 4(b) shows a comparison between these two methods, where the particle density function $\varrho(x)$ is given by the black line, the pink area under the line represents the particles not accounted for by the cluster approach (the ones outside the dotted line in Figure 4(a)), and the green area represents the extra particles added to try to compensate for the ones left out. The problem with DFA is that it is very computationally demanding, requires experimental data which is currently out of reach in regards to the OLR process, and solves problems very differently than classical macroscale thermodynamics. CA on the other hand, has been researched to a much greater extent, requires significantly less computational time, ${ }^{[11]}$ and uses a very similar mindset to that of classical macroscale thermodynamics, like sharing similar parameters/properties. Another benefit of a well defined phase boundary, like in $\mathrm{CA}$, is that the boundaries of a nuclei is clearly defined, which is required for assigning it certain thermodynamic phase properties. These phase properties are to list a few: volume $V\left[\mathrm{~m}^{3}\right]$, surface area $A_{s}\left[\mathrm{~m}^{2}\right]$, surface $\sigma_{i i}$ and interfacial energy density $\left.\sigma_{i j}\right|_{i \neq j}\left[\mathrm{~J} / \mathrm{m}^{2}\right]$ (which for liquids is the same as surface and interfacial tension), and particle count $\varsigma$ [\#particles]. In contrast, DFA's particle density function describes the phase and its transitional regimes as a whole. Seen in this context it makes no sense to assign a phase a surface area for instance, as it is in truth a mathematical construct and not a true physical property. While DFA provides a more accurate depiction of the physical world, it is difficult to combine with other micro/macro theories found in the literature, as its system description and parameters are fundamentally different to those traditionally used (along with its previously noted solvability issues). This makes it easier to compare and integrate CA with other micro/macro theories in the literature, as they share the same parameters and are built with similar mindsets. Thus at the current date, CA is preferred over DFA if possible.

When using CA to describe slag nucleation in OLR, the first challenge comes from CA not necessarily being applicable for nanoscale systems. For CA to be applicable it must first be demonstrated that the slag can be assumed to exhibit a clearly defined surface. This can be rephrased as a surface for which the surface tension $\sigma_{i i}$ is not a function of cluster size, or:

$$
\frac{d \sigma_{i i}}{d r} \approx 0
$$

Here $d r$ is the change in phase surface curvature which, assuming a given phase geometry like a sphere and a given particle density, can also be expressed by the number of particles in a phase $\varsigma_{p}$. A consequence of this is that the surface structure will be consistent regardless of the phase size.

This phenomenon can be visualized by picturing a surface consisting of small triangles, with a given size, approximating a sphere. Triangles can simply be added or removed to change its size without changing the surfaces overarching structure, as long as the sphere is large compared to the triangles themselves. However, if the sphere shrinks too much, the triangles will no longer be able to retain their approximate spherical shape. The surface structure must therefore change to accommodate this change in size, causing it to change its surface tension $\sigma_{i i}$. Kashchiev ${ }^{[1]}$ describes the thermodynamic surface tension for a droplet becoming less and less sensitive to changes in its curvature $\Delta \sigma_{i i}\left(\varsigma_{p}\right)$ as it becomes larger. This has also been shown by others, 
like the modeling work of Thompson et al. ${ }^{[13]}$ From Kashchiev and Thompson et al., $\varsigma_{p}>1000$ is here assumed as the size a slag nuclei/droplet needs to attain before CA is a generally applicable approximation. This is based on Kashchiev and Thompson et al.'s limits pertaining to simple liquids, where the proposed framework is based on the slag exhibiting non-simple behaviors while the nucleus is small.

Schweigert et al. ${ }^{[14]}$ have performed molecular modeling of $\mathrm{SiO}_{2}$ clusters over the range $T=1500-2800 \mathrm{~K}$, and found that its surface tension is relatively constant down to $24 \mathrm{SiO}_{2}$ molecules, implying that the surface structure does not change significantly with size. Hence, a $\mathrm{SiO}_{2}$ cluster may then be viewed as an outer surface shell encompassing the bulk. One aspect which must be noted about the results from Schweigert et al. is that their value for the surface tension of silica $\left(\sigma_{\mathrm{SiO}_{2}}([1999 \mathrm{~K}, 2300 \mathrm{~K}]) \approx[0.58,0.67] \mathrm{J} / \mathrm{m}^{2}\right)$ does not fit the literature value $\left(\sigma_{\mathrm{SiO}_{2}}([1999 \mathrm{~K}, 2300 \mathrm{~K}]) \approx\right.$ $\left.[0.30,0.31] \mathrm{J} / \mathrm{m}^{2}\right)$. This is attributed to the chosen interatomic potential being tuned for a bulk phase and not the surface, but the overall behavior of the cluster should still hold. Work by Roder et al. ${ }^{[15]}$ and Vaccaro et al. ${ }^{[16]}$ also found a similar shell-like structure in $\mathrm{SiO}_{2}$ nanoparticles, where Roder et al.'s model only covers higher temperatures and particle amounts and Vaccaro et al. measures the shell thickness experimentally at room temperature. Since this shell structure is found by multiple groups, it strengthens the notion that silica also has this structure at nanoscale. In OLR, due to the alloy mainly consisting of $\mathrm{Si}$, the slag nuclei is expected to start as pure $\mathrm{SiO}_{2}$. $\left(\mathrm{SiO}_{2}\right)$ will then react with $[\mathrm{Ca}]$ and [Al], as the nucleus grows. Until experiments are performed to verify/disprove the molecular modeling results of Schweigert et al. ${ }^{[14]}$, it is prudent to assume that the CA can be applied to the initial slag nucleus, if we assume that it consists of pure silica and contains more than $24 \mathrm{SiO}_{2}$ molecules, even though it might be a rough approximation. The next challenge comes in placing the dividing surface between the slag and both silicon melt and gas bubble. Thermodynamic phase properties like phase volume** are by default not

$* *$ Volume of the whole system is conserved and does not depend on the dividing surface, only the volume assigned to the specific phase.

necessarily equal to their physical counterparts as the $\mathrm{CA}$ is internally consistent for any arbitrary dividing surface. ${ }^{[9,10]}$ As such, a dividing surface must be chosen where the calculated thermodynamic properties and physical measurements align so that the theoretical surface is representative of the physical object. This is necessary to ensure that any calculated thermodynamic parameter will match its physical counterpart, as only the physical parameter can be measured.

Figure 4(c) shows one such way of placing the dividing surface, called an equimolar dividing surface. Here, the area in green shows the number of particles which do not get accounted for by placing the dividing surface as shown, similar to the particles outside of the

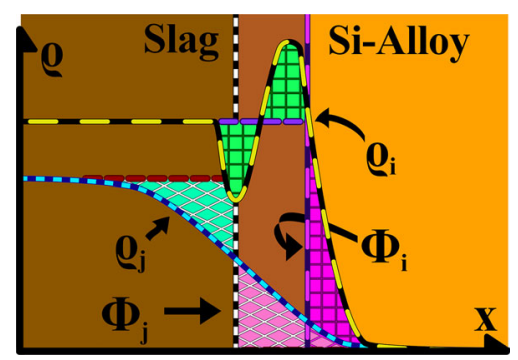

Fig. 5-Particle density functions $(\varrho(x))$ of the surface active species $i$ with lines in black and yellow, and the non surface active species $j$ in blue, where $\mathbf{x}$ represents distance from the bulk slag phase. $\Phi_{i}$ (purple and pink) and $\Phi_{j}$ (black and white) indicates the equimolar dividing surface.

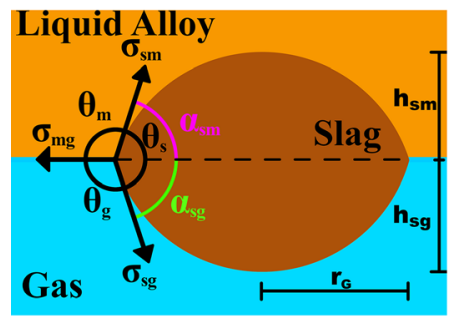

(a)

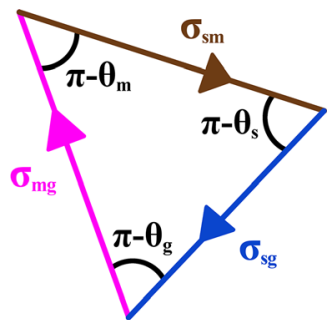

(b)
Fig. 6-(a) Three-fluid system. Interfacial tensions, $\sigma_{i j}$, and contact angles, $\theta_{i}, \alpha_{i j}$, are given. Droplet radius, $r_{G}$, and heights, $h_{s m}, h_{s g}$, are also shown. (b) Neumann Triangle in radians.

circle in Figure 4(a). To compensate, an equal amount of particles are added to the slag, here shown in pink. This placement of the dividing surface thus conserves the number of particles in each phase, making it equimolar. In multicomponent phases, each individual components density function $\varrho_{p, i}$ will not necessarily align as each species may exhibit different degrees of surface activity, adding extra layers of complexity in placing a representative dividing surface.

As such, if a single species is much more surface active than the others, it might define the surface, meaning this species alone can be used as a guide to place a surface which is more representative of the phase as a whole, like depicted in Figure 5. Figure 5 shows the particle density functions of two species $i$ and $j$, where species $i$ is surface active while $j$ is not. From the figure, one can see that the equimolar dividing surface given by species $i$, provides a more representative boundary between the slag and metal melt than the dividing surface from species $j$. How $\mathrm{Al}$ and Ca affect the slag will be discussed further in Section II-C. This section will continue with the nucleation of pure silica nuclei, formulating an expression of the slag's initial nucleus size, assuming CA.

Here it is assumed that the nucleus behaves closer to that of a liquid than a rigid solid, even though the initial nucleus is assumed to consist solely of silica, which melts at $1725^{\circ} \mathrm{C}$, and temperatures in OLR are generally in the range of $1500{ }^{\circ} \mathrm{C}$ to $1700{ }^{\circ} \mathrm{C}$. Hence, the properties of liquid silica will be used if not otherwise specified. Due to its size regime and the structural comparison/transition of amorphous silica to its liquid form, coupled with 
the reactions exothermic nature, this assumption is thought to be acceptable, while a similar approach can be performed with a rigid solid nucleus as well.

One could argue that a higher temperature should be used due to the highly exothermic nature of silicon's reactions with oxygen. This is not considered in this work, but if this is the case then it will further strengthen the assumption that silica behaves a liquid and not a rigid solid. Some slight indications that a higher temperature should be used will be seen later when discussing Figure 8. A small molten slag droplet which rests on a gas bubble surface in a metal melt gives a three-fluid system, and is thus assumed to satisfy Neumann's vector relation such that it exhibits a lens shape. ${ }^{[1]}$ Figure 6(a) illustrates the three-fluid system, where it can be seen that the interfacial tension vectors are separated by the phase angle for each phase $\theta_{s}, \theta_{m}$, and $\theta_{g}$. The lens can further be divided into two spherical caps, dividing $\theta_{s}$ into contact angles between the slag/melt $\alpha_{s m}$ and gas/slag $\alpha_{s g}$, with limits:

$$
0<\theta_{s}<180^{\circ} \quad 0<\left(\alpha_{s m}, \alpha_{s g}\right)<90^{\circ}
$$

It is convenient to visualize how the vectors in Figure $6 \mathrm{a}$ relate to each other as a triangle, commonly known as a Neumann Triangle and can be seen in Figure 6(b). Using this triangle, one can express how the interfacial tensions relate to each other and the phase angles, like for instance the interfacial tension between slag and melt $\sigma_{s m}$ can be expressed as:

$$
\sigma_{s m}=\sqrt{\sigma_{m g}^{2}-\sigma_{s g}^{2} \sin ^{2}\left(\theta_{s}\right)}-\sigma_{s g} \cos \left(\theta_{s}\right)\left[\frac{J}{m^{2}}\right]
$$

An expression for the initial slag nucleus size can then be formulated:

$$
\begin{gathered}
n^{\star}=\frac{32 \pi}{3} \frac{V_{0, m o l}^{2} \sigma_{s m}^{3}}{\Delta \mu^{3}} f\left(\alpha_{s m}, \alpha_{s g}\right)[m o l] \\
f\left(\alpha_{s m}, \alpha_{s g}\right)=\psi\left(\alpha_{s m}\right)+\left(\frac{\sin \left(\alpha_{s m}\right)}{\sin \left(\alpha_{s g}\right)}\right)^{3} \psi\left(\alpha_{s g}\right) \\
\psi\left(\alpha_{i j}\right)=\frac{\left(2+\cos \left(\alpha_{i j}\right)\right)\left(1-\cos \left(\alpha_{i j}\right)\right)^{2}}{4}
\end{gathered}
$$

Here, $V_{0, m o l}\left[\mathrm{~m}^{3} / \mathrm{mol}\right]$ is the molar volume of the species the nuclei consists of at nucleation (here $\mathrm{SiO}_{2}$ ), $\Delta \mu[\mathrm{J} / \mathrm{mol}]$ is the thermodynamic chemical potential driving the nucleation, and $f\left(\alpha_{s m}, \alpha_{s g}\right)$ is a geometric term to account for the fact that we have a lens and not a sphere. How to generate these equations, together with a more in depth coverage of nucleation itself is described by Kashchiev 11.

The driving force for nucleation in the case of OLR can be expressed as a local over-saturation of dissolved oxygen in the melt, as this allows $\mathrm{Si}$ to react with oxygen in the first place. This over-saturation can be expressed as the change in chemical potential resulting from the

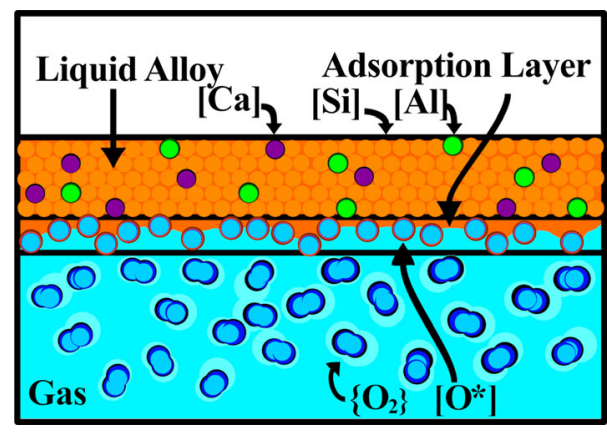

Fig. 7-Schematic representation of the melt/gas interface.

difference in the activity of silica at the oxygen saturation limit in silicon, and the activity of silica when in contact with the gas phase, the bubbles, shown in Figure 7. This will also account for the formation of $\{\mathrm{SiO}\}$. Assuming that the activity of silicon does not change in the melt, the chemical potential can be expressed as

$$
\begin{gathered}
\Delta \mu=-R T \ln \left(\frac{a_{\left\{O_{2}\right\}}}{a_{[O]}^{2}}\right) \\
\lim _{[\text {wtpctO }] \rightarrow 0} a_{[O]}=c_{[O], s a t}
\end{gathered}
$$

Here $a_{[O]}$ is the activity of [O], assumed to be equal to the dimensionless oxygen saturation concentration in silicon with respect to $1 \mathrm{wt}$ pet dissolved species in molten $\mathrm{Si}, c_{[O], \text { sat }} . a_{\left\{\mathrm{O}_{2}\right\}}$ denotes the activity of oxygen in the gas bubble with respect to a 1 bar reference state. It should be noted that the reason $a_{\left\{O_{2}\right\}}$ is used instead of dimensionless oxygen pressure in the gas $p_{\left\{O_{2}\right\}}$, is due to that the oxygen concentration in the bubbles that the melt sees might not be equal to the bulk oxygen partial pressure of the bubble. Næss [18] concludes from experiments and existing literature that there is a maximum bulk oxygen partial pressure for active oxidation of a still silicon surface of $2 \cdot 10^{-3} \mathrm{~atm}$. She also shows that there is a clear distinction between oxygen which is available for silicon to react with, and the oxygen in the bulk gas. From a thermodynamic point of view, this means that one cannot use the common assumption that partial pressure and activity are the same, thus necessitating the use of $a_{\left\{O_{2}\right\}}$ over $p_{\left\{O_{2}\right\}}$.

As thermodynamics is concerned, the number of particles in a nucleus and its geometry are coupled. Thus, if one can express the initial nucleus size like in Eq. [9], there also has to be a way to express the necessary spatial parameters to define the initial nucleus' surface area and volume. For a lens these spatial parameters are its angles, which can be found from Eq. [8], and the lens radius, which is half of the stippled line in Figure 6(a). The initial nucleus size, also called the critical nucleus size, has a critical radius $r_{G}^{\star}$, which can be expressed as: 

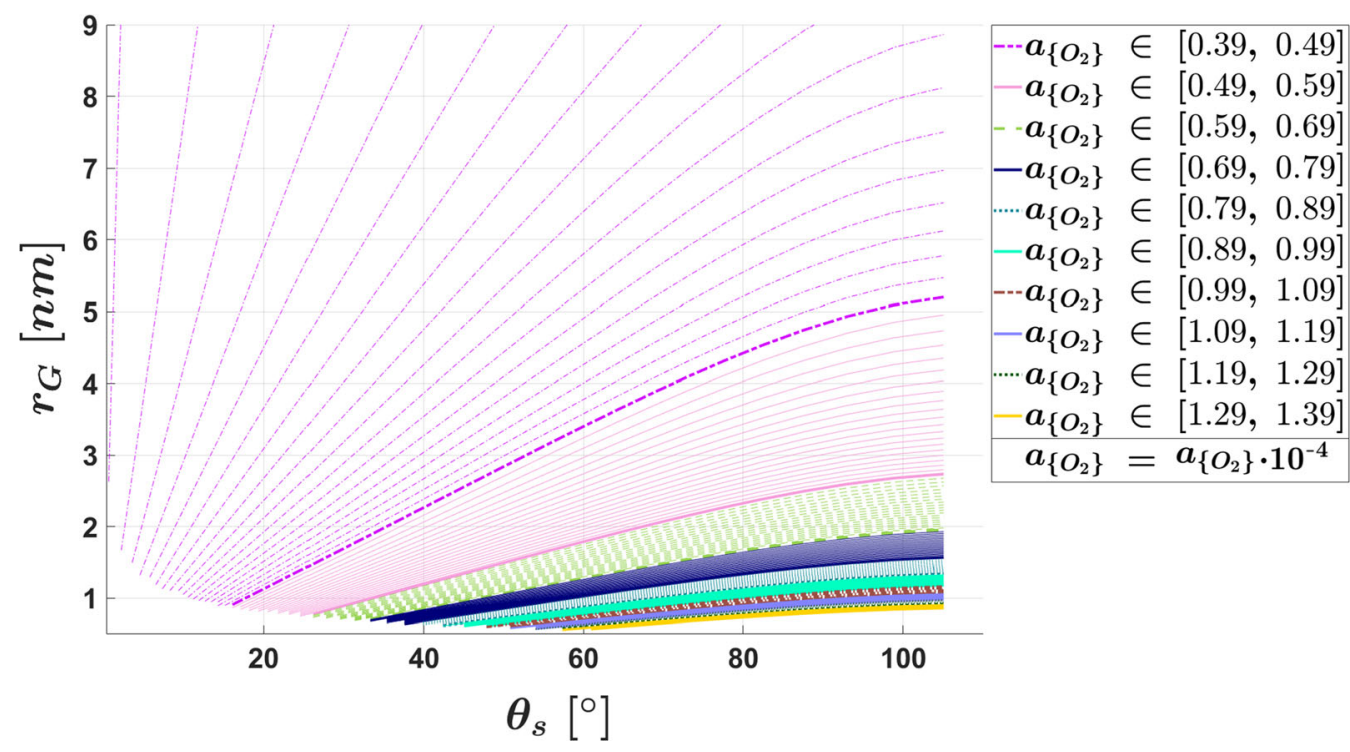

Fig. 8- $r_{G}^{\star}$ as a function of the slag's contact angle $\theta_{S}$ and the oxygen activity in the gas $a_{\left\{\mathrm{O}_{2}\right\}}$ ( $a_{\left\{\mathrm{O}_{2}\right\}}$ in the legend must be multiplied by $10^{-4}$ to get the actual value). Each line represents a different activity, and lines are grouped together by color/line style, where each color/line style represents a span of $10^{-5}$. Parameters used can be found in Table II.

$$
r_{G}^{\star}=-\frac{2 \sigma_{s m} V_{0, m o l}}{R T \ln \left(c_{[O]}^{2} / a_{\left\{O_{2}\right\}}\right)} \sin \left(\alpha_{s m}\right)[m]
$$

Contact angles, like $\theta_{s}$, are expected to have a specific value in a given system and thermodynamic state, which here is linked to the interfacial tension between slag and alloy $\sigma_{s m}$ through Eq. [8]. The problem is that neither $\sigma_{s m}$ nor $\theta_{s}$ are currently known, so the other cannot be calculated directly for given values of $\sigma_{m g}$ and $\sigma_{s g}$. This problem can be somewhat circumvented by looking at the range of all possible values which either $\sigma_{s m}$ or $\theta_{s}$ may take at a given state, along with how this range of attainable values gets affected as other system properties/parameters change. Sections II-C and II-E delve deeper into how slag composition affects the range of attainable values, while this section will look at how the oxygen activity in the purge gas will restrict the geometries a critical silica nuclei my have. If Eq. [14] is plotted as a function of the slag's total contact angle $\theta_{s}$ for different oxygen activities in the gas $a_{\left\{O_{2}\right\}}$, Figure 8 is generated. Here, each line has a different $a_{\left\{O_{2}\right\}}$, where lines are grouped together by color to increase clarity, with each color representing an oxygen activity span of $10^{-5}$, where the span size itself was not chosen for its physical significance, but rather to show the trend more clearly. The white space in the bottom left hand corner is due to a requirement that the nuclei must consist of one or more molecules, and the cut off on the right hand side is due to overstepping the boundaries in Eq. [7]. $3.90 \cdot 10^{-5}$ was chosen as the lowest $a_{\left\{O_{2}\right\}}$ boundary due to it being the lowest oxygen activity which gives $\mathrm{SiO}_{2}$ clusters consisting of at lest one molecule. It must be noted that $3.90 \cdot 10^{-5}$ is about two order of magnitude lower than the maximum bulk oxygen partial pressure for active oxidation of a still silicon surface $\left(2 \cdot 10^{-3}\right.$ atm) from Næss 18. This indicates that the oxygen activity can only take values which are between the formation activity and an activity representing the oxygen activity at maximum active oxidation. This is also true for the model used here, as when the oxygen activity becomes too high, only nuclei containing less than one $\mathrm{SiO}_{2}$ molecule will form, which is not a valid solution. At $1823 \mathrm{~K}$, this happens at $a_{\left\{O_{2}\right\}} \approx 4.85 \cdot 10^{-4}$. The model represented in Figure 8 is valid for activities of the same order of magnitude as that of Næss, but only for temperatures above approximately 2000 $\mathrm{K}$, which coincides with the melting temperature of silica $(1999 \mathrm{~K})$. The nature of this connection between the model presented here and the work of Næss is not currently known, but if it exists it might shine some light on how $a_{\left\{O_{2}\right\}}$ behaves, and how it relates to the oxygen partial pressure in the bulk gas.

Figure 8 allows for prediction of the critical nuclei behavior, without necessarily knowing the oxygen activity in the gas $a_{\left\{O_{2}\right\}}$ or the lens shape. As $a_{\left\{O_{2}\right\}}$ increases, Figure 8 predicts that the critical nuclei will take less space on the bubble surface as the radius decreases. Consequently, the possible geometries available for the slag droplet to take, get constrained toward higher contact angles. This results in a configuration where the bubble can support higher populations of slag nuclei, and that each slag droplet can attain a higher volume than it otherwise would, due to exhibiting a sharper convex surface toward the gas and melt.

To Figure 8, lines can be added which indicate the critical radius of a nuclei containing a given number of $\mathrm{SiO}_{2}$ molecules. This results in Figure 9. Each group of similarly colored lines in Figure 8 represent the same change in the oxygen activity inside of the gas bubble. Line groups at higher $a_{\left\{O_{2}\right\}}$ are closer together forming a 


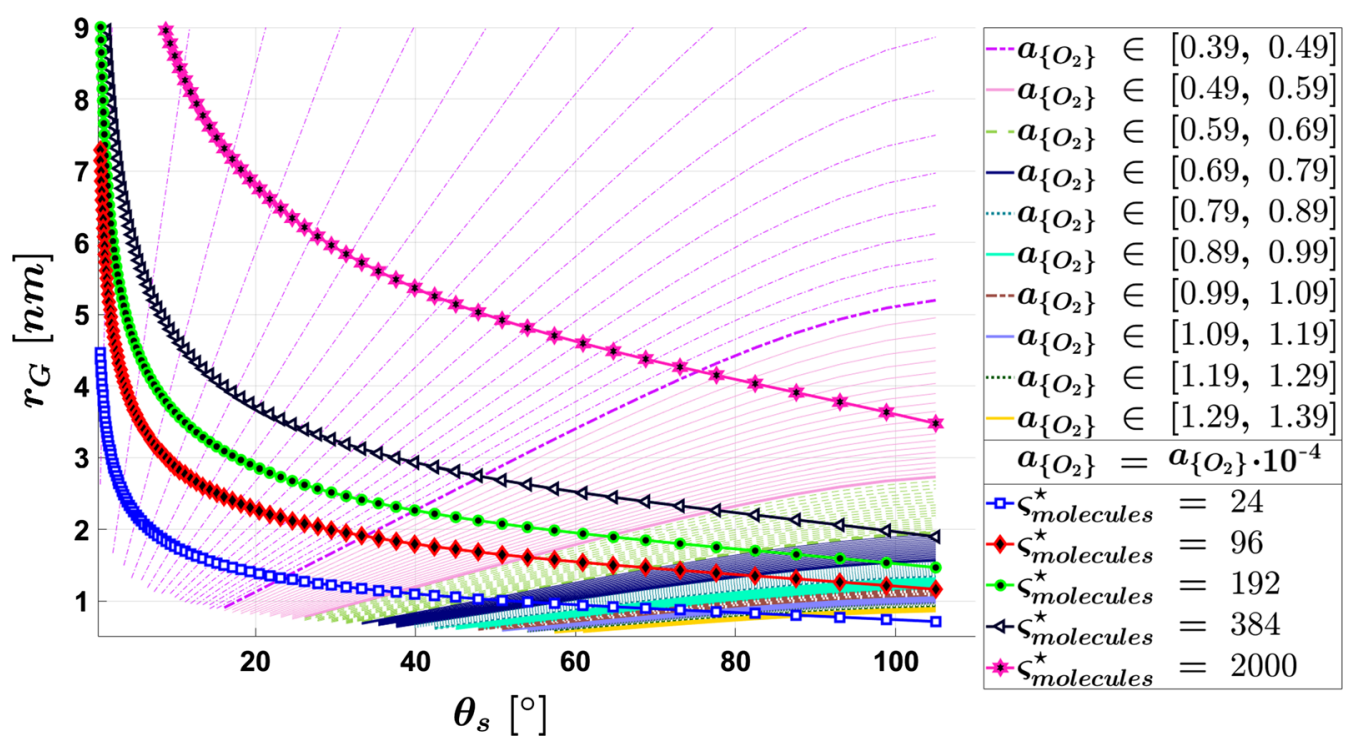

Fig. 9 -Figure 8 with lines indicating the number of $\mathrm{SiO}_{2}$ molecules in the critical nucleus. These lines use densities from $\mathrm{Sweigert}$ et al. 14 and transforms a sphere with said density into a lens. For a lens $r_{G}$ is a function of $\theta_{s}$ which is then plotted.

tighter color band, as the critical radius becomes less sensitive to the oxygen activity in the gas with increased activity. This means that a critical nucleus containing a given amount of molecules will have to change its contact angle less to accommodate a higher oxygen activity in the gas $a_{\left\{O_{2}\right\}}$, as seen in Figure 9. Higher oxygen activities also put greater restrictions on the number of molecules in the critical nucleus, its radius, and its allowed angles. From the fourth line grouping (dark blue) and onward, the critical nucleus cannot contain more than 384 molecules, its radius must be less than $2 \mathrm{~nm}$, and the total slag angle $\theta_{s}$ must be larger than $32^{\circ}$. In general Figure 9 predicts that a higher oxygen content in the bubble will result in smaller slag nuclei being formed with steeper contact angles. It thus predicts that increasing the oxygen content in the purge gas, and by extension the oxygen activity in the gas $a_{\left\{O_{2}\right\}}$, should result in an increased refining rate. The amount of oxygen in the purge gas is one of the few industrial control parameters available in OLR, making this connection between oxygen amount and critical nucleus size and geometry valuable not only for research purposes, but also for further industrial process control. It must however be noted that increasing the amount of oxygen in the bubble also has other effects. If there is too much oxygen in the bubbles, then one could picture a scenario where silica is produced too quickly to facilitate a smooth transition from $\mathrm{SiO}_{2}$ to $\mathrm{SiO}_{2}-\mathrm{CaO}-\mathrm{Al}_{2} \mathrm{O}_{3}$ slag. The high viscosity of silica should make diffusion slower for the impurities, but if the diffusion length is small then this becomes less of an issue. If the slag droplet gets too large however, then this will likely reduce the refining rate instead of increasing it.

\section{C. "Well Defined" Surfaces in $\mathrm{SiO}_{2}-\mathrm{CaO}-\mathrm{Al}_{2} \mathrm{O}_{3}$ Slags}

The previous section shows how the initial slag nuclei can be described by CA, when it is assumed that it consists of pure silica. As the slag nuclei grows it will react with $[\mathrm{Ca}]$ and $[\mathrm{Al}]$, forming a $\mathrm{SiO}_{2}-\mathrm{CaO}-\mathrm{Al}_{2} \mathrm{O}_{3}$ slag. If this occurs before the number of particles in the nucleus $\varsigma_{p}$ becomes higher than 1000 , then we must consider if CA is still applicable. In this section we will show that there are clear indications that $\mathrm{SiO}_{2}$ defines the surface structure of $\mathrm{SiO}_{2}-\mathrm{CaO}-\mathrm{Al}_{2} \mathrm{O}_{3}$ slags, at least at high silica concentrations $\left(X_{\left(\mathrm{SiO}_{2}\right)}^{\text {surface }} \geq 0.9\right)$. Assuming that the nuclei will grow large enough before $\mathrm{SiO}_{2}$ starts to loose control over the surface seems reasonable, as the availability of [Si] is much higher compared to [Ca] or [Al]. With this assumption, the droplet growth can be scaled, expressed, and defined even as it transitions between different spatial regimes.

The exact concentration at which this transition occurs is currently not known for $\mathrm{SiO}_{2}-\mathrm{CaO}-\mathrm{Al}_{2} \mathrm{O}_{3}$ slags, but Waseda and Toguri 23 states that any addition of alkali metal oxide beyond $10 \mathrm{~mol}$ pet will gradually change the fragmented random covalent network of silica into an ionic liquid. This compares well with the experimental work of Bockris et al.,24 which states that the silica framework will "collapse" when sufficient metal oxide is added, which they write is in the rage of 10-12 mol pct. Bockris et al., 24 also provides a possible method for how the collapse occurs, which is later expanded on in Richardson 25 by including more of the then available literature.

While liquids, unlike solids, do not show long range structure they still exhibit short range, and in some instances intermediate range, structure. The intermediate range structure exhibited by molten silica, like the one shown by Waseda and Toguri, is presumably the reason for why the silica surface can be described as "well defined", satisfying Eq. [6]. That silica retains this property even at nanoscale, indicates that the surface structure is very favorable, which in turn implies that it is at an energy state not that much higher than the bulk molecules. Silica's relatively low surface tension also supports this, as surface tension can also be expressed as the energy difference between the surface and bulk. 
Systems will tend toward minimizing its energy state, so if a phase consists of multiple species, then a lower surface energy state can be achieved by allowing the species with the lowest surface energy state to be positioned at the surface. Thermodynamically, this is represented by a surface activity, and causes a different species concentration at the surface compared to the bulk phase. Surface activity can be quantified by looking at how each species affects the total surface energy density/surface tension of the slag $\sigma_{s} . \sigma_{s}$ can be estimated using a model based upon the Butler equation from Tanaka 26, solving the equation set:

$$
\sigma_{s}=\sigma_{i}^{\circ}+\frac{R T}{\bar{A}_{i}} \ln \left(\frac{a_{i}^{s}}{a_{i}^{b}}\right)
$$

Here $\bar{A}_{i}\left[\mathrm{~m}^{2} / \mathrm{mol}\right]$ is the surface molar coverage for species $i$, and $a_{i}$ is the species Raoultian activity with a pure species in mole fraction as its reference state, where $b$ or $s$ in the superscript designate either surface or bulk respectively. Nakamoto et al. 27 and 28], Fabritius et al. 29 and Hanao et al. 30 have shown that this model approximates the surface tension $\sigma_{s}$ for different ternary slag compositions consisting of $\mathrm{SiO}_{2}$, $\mathrm{Al}_{2} \mathrm{O}_{3}, \mathrm{CaO}, \mathrm{FeO}, \mathrm{MgO}$, and $\mathrm{MnO}$ quite well.

It must be noted that in the desired temperature range $\mathrm{T}=1500{ }^{\circ} \mathrm{C}$ to $1700{ }^{\circ} \mathrm{C}$ the pure slag components will not be liquid, but the model treats them as such. For reference, $\mathrm{SiO}_{2}$ melts around $1727^{\circ} \mathrm{C}$, and both $\mathrm{CaO}$ and $\mathrm{Al}_{2} \mathrm{O}_{3}$ melt at different temperatures higher than $2000^{\circ} \mathrm{C}$. The specifics of the model and its viability is discussed extensively in the respective referenced literature.

It is well documented that the structures and properties of oxide melts are controlled by the concentration and potency of its network-formers and -modifiers. Silica is a potent network-forming oxide, imposing structure in the melt. Calcia on the other hand, is a strong network-modifier, breaking down the melt structure, while alumina is an amphoteric oxide, behaves either as a network-former or -modifier depending on slag composition. Silica imposes a structure consisting of more or less coupled $\mathrm{SiO}_{4}^{4-}$ monomers, whose degree of polymerization depends on the surrounding slag. In the slag, alumina can reach its lowest energy state by acting as if it was silica. By sharing one $\mathrm{Ca}^{2+}$ ion between two $\mathrm{Al}^{3+}$ ions, charge neutrality is reached, while also allowing each $\mathrm{Al}^{3+}$ ion to act as if it were $\mathrm{Al}^{4+}$, mimicking $\mathrm{Si}^{4+}$. Other structures for $\mathrm{Al}^{3+}$ are also possible, but they require higher energy states. Calcia acts only to disrupt the silica structure. As silica imposes structure, increasing properties like dynamic viscosity and lowering the diffusion rate, calcia will disrupt said structure, and in turn lower the slag viscosity and increase the diffusion rate. Calcia thus plays a vital role in forming the $\mathrm{SiO}_{2}-\mathrm{CaO}-\mathrm{Al}_{2} \mathrm{O}_{3}$ slag, as it provides new $\mathrm{Al}$ and $\mathrm{Ca}$ ions easier access to the bulk slag, while also facilitating the uptake of $\mathrm{Al}^{3+}$ ions by allowing a lower energy structural configuration. Alumina can also disrupt the structure of silica if the relative concentration of calcia is low, but is a much less disruptive than calcia.
These structural behaviors can also be seen by solving Eq. [15], as shown in Figure 10. The iso-tension lines were calculated by solving Eq. [15] at a given $\sigma_{s}$ and $X_{\left(\mathrm{SiO}_{2}\right)}^{b}$. As $\sum X_{i}=1$ is true for both surface and bulk concentrations, this allows the equation set to be solved with three unknowns $\left(X_{(\mathrm{CaO})}^{s}, X_{(\mathrm{CaO})}^{b}, X_{\left(\mathrm{SiO}_{2}\right)}^{s}\right)$ and three equations. Expressions for species surface tension $\sigma_{i}^{\circ}$ and surface molar coverage $\bar{A}_{i}$ were taken from Arutyunyan et al. 31 .

Figure 10(a) shows that the bulk concentration of calcia has a much greater impact on the surface structure than that of alumina, even though $\sigma_{s}$ is most sensitive to the slag's bulk silica concentration. This is seen by how the iso-tension lines follow paths which all fall between the iso-concentration lines of silica and calcia, which states that the iso-tension lines follow constant calcia to silica ratios in the bulk. The lines are however not completely straight, and which ratios they follow differ, but the trend is quite clear to see. In Figure 10(b) it can also be seen that the surface composition reflects this trend, but here the concentration of silica is even more dominant. This trend is consistent with the theory, as if $\mathrm{Al}^{3+}$ gets to act as $\mathrm{Al}^{4+}$ in the slag, it will only cause the slag structure to deviate slightly from that of pure silica, which should only cause a slight increase in the energy state and thus the slag surface tension $\sigma_{s}$. Significant deviations in $\sigma_{s}$ are only shown when greater amounts of alumina are added. Calcia is the principal network-modifier, so its effect on the surface should overshadow that of alumina. However, increasing the concentration of any of the species at the cost of silica will have the greatest effect.

When Figures 10(a) and (b) are seen side by side, it shows that the slag's bulk composition can change quite drastically, while only causing minor changes in surface concentration. Since the surface concentration of silica changes less than that of the bulk when calcia and alumina are added, indicates that silica is surface active while alumina and calcia are not. In Eq. [15] the reference surface tension for species $i \sigma_{i}^{\circ}$ and $R T / \bar{A}_{i}$ will be positive values. $\sigma_{(\mathrm{CaO})}^{\circ}$ and $\sigma_{\left(\mathrm{Al}_{2} \mathrm{O}_{3}\right)}^{\circ}$ both will be higher than $\sigma_{s}$, while $\sigma_{\left(\mathrm{SiO}_{2}\right)}^{\circ}$ is smaller, at $1873 \mathrm{~K}$. The only way to satisfy the equation set is then for:

$$
a_{\left(\mathrm{SiO}_{2}\right)}^{s}>a_{\left(\mathrm{SiO}_{2}\right)}^{b}, a_{(\mathrm{CaO})}^{s}<a_{(\mathrm{CaO})}^{b}, a_{\left(\mathrm{Al}_{2} \mathrm{O}_{3}\right)}^{s}<a_{\left(\mathrm{Al}_{2} \mathrm{O}_{3}\right)}^{b}
$$

If $a_{i}^{s}>a_{i}^{b}$ the species must be surface active, leading to it possessing a higher surface presence than its bulk concentration would imply. $a_{i}^{s}<a_{i}^{b}$ on the other hand causes the species to withdraw from the surface and congregate in the bulk. From this it is quite clear the model predicts that silica is highly surface active, while both calcia and alumina prefer the bulk slag. Figures 10(a) and (b) show that this allows the slag to retain a surface concentration of more than 90 mol pct silica, even though the silica concentration in the bulk slag is much lower. This allows the slag to retain its "well defined" surface over a wide range of bulk compositions, allowing the approximation to still be valid even though different slag nuclei may experience 


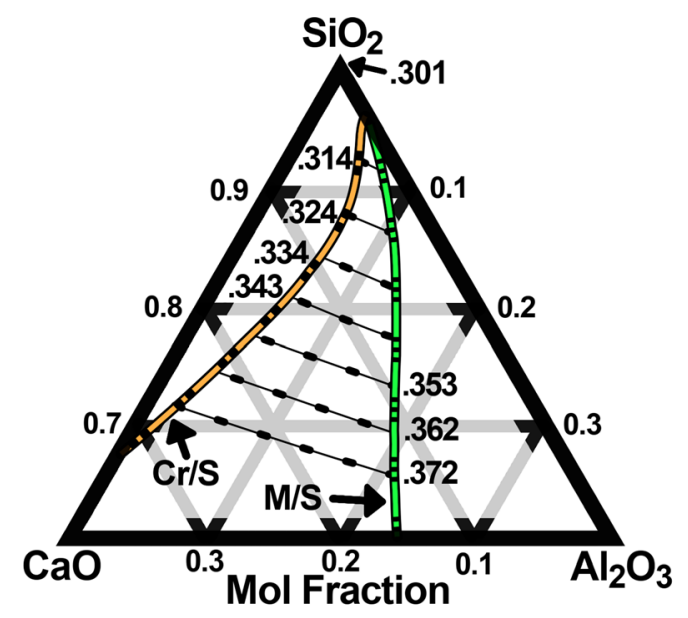

(a)

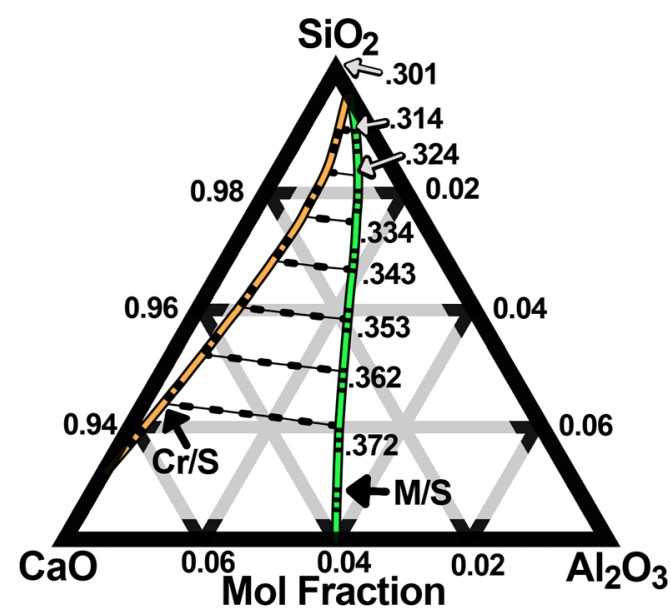

(b)

Fig. 10 - Slag surface tension $\sigma_{s}\left[\mathrm{~J} / \mathrm{m}^{2}\right]$ at different surface/bulk slag concentrations, calculated with the model from Tanaka 26 at $1873 \mathrm{~K}$. The iso-tension lines cover the concentrations where the slag is liquid, and is flanked by the cristobalite/slag(liq) (Cr/S) line and the mullite/slag(liq) $(\mathrm{M} / \mathrm{S})$ line. (a) $\sigma_{s}$ at different bulk slag concentrations. (b) Shows the surface concentrations corresponding with the iso-tension lines and Cr/S, $\mathrm{M} / \mathrm{S}$ lines in a).

compositional variations before they reaches a size of 1000 particles. Showing that the "well defined" surface is resistant to compositional variation is critical, as a high sensitivity would limit its practical use due to the high variance associated with high temperature processes.

Some notes on the model used in this section and a comparison with other authors: Arutyunyan et al. 31 models the slag's surface tension $\sigma_{s}$ for $\mathrm{CaO}-\mathrm{Al}_{2} \mathrm{O}_{3}$, $\mathrm{CaO}-\mathrm{SiO}_{2}$, and $\mathrm{SiO}_{2}-\mathrm{CaO}-\mathrm{Al}_{2} \mathrm{O}_{3}$ melts, with respect to concentration and temperature. They additionally compare their results with experimental data from multiple other authors. While the spread in experimental values are quite significant, they share similar trends with Tanaka's 26 model. Increasing the amount of calcia and/or alumina in the bulk slag, increases $\sigma_{s}$ both in the case of $\mathrm{CaO}-\mathrm{SiO}_{2}$ and $\mathrm{SiO}_{2}-\mathrm{CaO}-\mathrm{Al}_{2} \mathrm{O}_{3}$. Tanaka's model was also compared with values from a slag atlas. ${ }^{[32]}$ Here the seven listed experimental values with $X_{\left(\mathrm{SiO}_{2}\right)}^{b}$ above 0.6 would overshoot the modeled values by between 0.0022 and $0.0627 \mathrm{~J} / \mathrm{m}^{2}$ at a $95 \mathrm{pct}$ confidence. Arutyunyan et al. 31 also has a positive $d \sigma_{s} / d T$ for $\mathrm{CaO}-\mathrm{SiO}_{2}$ and $\mathrm{SiO}_{2}-\mathrm{CaO}-\mathrm{Al}_{2} \mathrm{O}_{3}$, but only for high concentrations of $\mathrm{SiO}_{2} . \quad d \sigma_{s} / d T$ will then become negative as the amount of calcia and alumina combined get too large. Still, at high concentrations of silica their model also alludes to silica defining the surface, which results in the silicon alloy perceiving the slag surface as only consisting of silica until the concentrations of alumina and calcia become high enough to start influencing the surface concentration, and thus the surface structure, themselves.

\section{Slag Growth}

Interfacial tension is in general affected by chemical reactions through effects like surface convection and Marangoni effects. If one has a pure silica slag droplet on a non-reactive gas substrate in a liquid silicon alloy, one would expect the contact surface between the slag and alloy to reduce its curvature as to increase the contact area. This can be seen as the surface spreading the burden of reaction over as large of an area as possible, by reducing surface curvature. A higher curvature can be retained once the droplet gets close to equilibrium with its surroundings.

For the system relevant to this work, this may not be case. As the gas bubble enters the silicon alloy, oxygen from the gas will over-saturate the silicon locally, which in turn will next to instantaneously form silica, which goes on to form the critical nuclei. The bubble will then be covered by small silica nuclei which act as seeds for further slag growth, however the greater their surface coverage the lower the oxygen flux between gas and liquid alloy will be. While it is convenient to think of the addition of calcia and alumina in the form of reactions, as shown in reaction 3 and 4 , this might not represent the whole story. On the silica surface there will be certain points where an oxygen atom will stick out of the surface ring structure, as can be seen in Roder et al. 15, Schweigert et al. 14, and Vaccaro et al. 16. Following the logic in Bromley et al. 33 these points should be the primary reaction centers, and additionally provide an attachment point for new silica molecules. When these oxygen atoms react with a particle the surface must deform to more firmly bind it to the structure. In the case of the impurities there are interesting ways 
Table II. Values Used to Generate Fig. 8

\begin{tabular}{lcc}
\hline $\mathrm{V}_{0, \text { mol }}\left[\frac{m^{3}}{m o l}\right]$ & $27.516\left(1+(T-1773) \cdot 10^{-4}\right) \cdot 10^{-6}$ & {$[19]$} \\
$\log _{10}\left(c_{[O]}\left[\frac{w t \% O}{1 w t \% O}\right]\right)$ & $-\frac{4620}{T}+0.332$ & {$[20]$} \\
$\sigma_{s g}\left[\frac{J}{m^{2}}\right]$ & $(243.2+0.031 T) \cdot 10^{-3}$ & {$[21]$} \\
$\sigma_{m g}\left[\frac{J}{m^{2}}\right]$ & $0.82-3 \cdot 10^{-4}(T-1685)$ & {$[22]$} \\
$\mathrm{T}[K]$ & 1823 & \\
\hline
\end{tabular}

Marangoni effects may cause the surface to locally fold, delivering the impurity away from the surface while simultaneously exposing new oxygen atoms.

In this work we argue that the slag nuclei will grow so rapidly, due to the low solubility of oxygen in silicon (see Table II), that any reduction in curvature from reactions between the slag and impurities is negligible. Instead, as the nucleus grows new silica molecules will use the underlying structure as a scaffold to further expand upon. [Ca] and [Al] will react with the surface, and in doing so disrupting said scaffold increasing the surface's energy state. This continuous growth will thus allow calcia and alumina to quickly enter the bulk slag while still affecting the surface structure. It will also spread them more evenly throughout the slag, lessening the need for diffusion, Marangoni effects, and allowing alumina to more quickly take its low energy configuration, while also solving potential ionic drag issues related to the local charge balance. It is further conjectured that since silica has an exceptionally favorable surface structure, this continuous growth provides a situation which is more similar to that at equilibrium, than that at which the curvature decreases. This also means that the "well defined" surface assumption still holds, and that the general thermophysical properties can be used. Here calcia and alumina get to affect the geometry by modifying the structure, like in the equilibrium case, but as their addition occurs over the whole growth cycle this will not cause the sudden changes needed for a large decrease in curvature. It must be noted, that for a slag nuclei/droplet to get ejected from the bubble surface it must either detach itself from the bubble substrate, which requires a very large curvature, or extend far enough from the bubble surface to get ripped of by the flow field, which gets stronger further away from the bubble surface. Size and curvature are thus important properties, as they both contribute to how far a nuclei/droplet may extend itself away from the bubble surface. A problem with the low curvature case, is that the slag nuclei/droplet would need to reach equilibrium with the surrounding alloy to allow higher curvatures. To compensate for shifts in the local alloy composition, and thus the slag's target equilibrium composition, it also seems likely that the nuclei/droplet would need to grow very large before its curvature could be increased. Since these events must happen in sequence, any external event/effect which negatively impacts the rate at which either event occurs will equally affect the process as a whole.

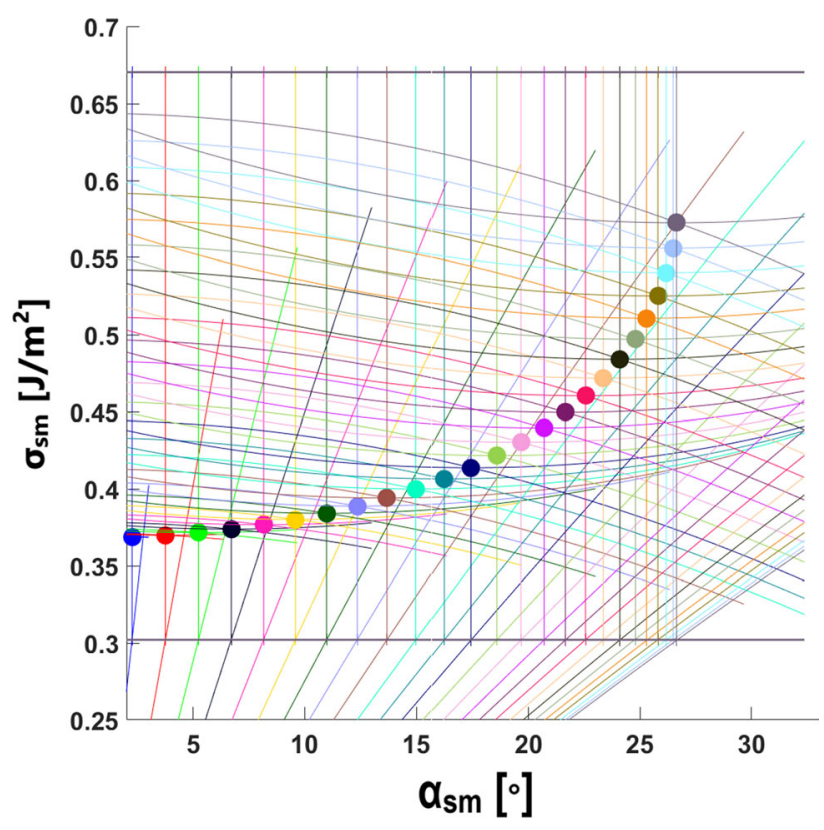

Fig. 11-Plot of different relationships between a triangles sides and angles from Fig. 6 b, where the interfacial tension between slag and melt $\sigma_{s m}$ is a function of the wetting angle between slag and melt $\alpha_{s m}$. Valid solutions are marked with circles. $\theta_{s} \in[5,179]^{\circ}$, $\alpha_{s m}=\arcsin \left(\left(\sigma_{s g} / \sigma_{m g}\right) \sin \left(\theta_{s}\right)\right)$. Valid solutions of $\sigma_{s g}, \sigma_{m g}$ are approximated as $\sigma_{s}^{\circ}, \sigma_{m}^{\circ}(1900 K)$, and uses the same expressions as in Table II.

It must be noted that this behavior should vary as the bubble travels through the ladle. In industrial ladles it is common to find what is colloquially called a "sponge" or a "mushroom". This is a collection/structure of slag found quite close to/on the porous plug, which is high in calcia. Calcia has a higher oxygen affinity than alumina, which suggest that just as the gas enters the melt there will be formed a large amount of slag very quickly. As the bubble ascends it will gradually get depleted of oxygen which will decrease the oxygen flux toward the alloy, slowing down or even stopping the production of new slag. This is however mitigated somewhat by there being a maximum bulk oxygen partial pressure for active oxidation of the silicon surface, as concluded by Næss 18. This works in the favor of the rapid growth hypothesis, as it means that the gas bubble has a limit to how quickly oxygen can be depleted, such that the rapid growth can occur over larger parts of the bubbles ascent. Local and ladle wide depletion of impurities is also a factor which will impede slag growth, and will be discussed further in the next section.

It must be stated that this is a hypothesis, as the authors have not found these complex interactions satisfactorily explored in the current literature to validate it until further work has been conducted. This work will continue to explore the effect of calcia and alumina on the slags geometry as if the proposed conjecture is true, as it sheds light on several interesting behaviors. 


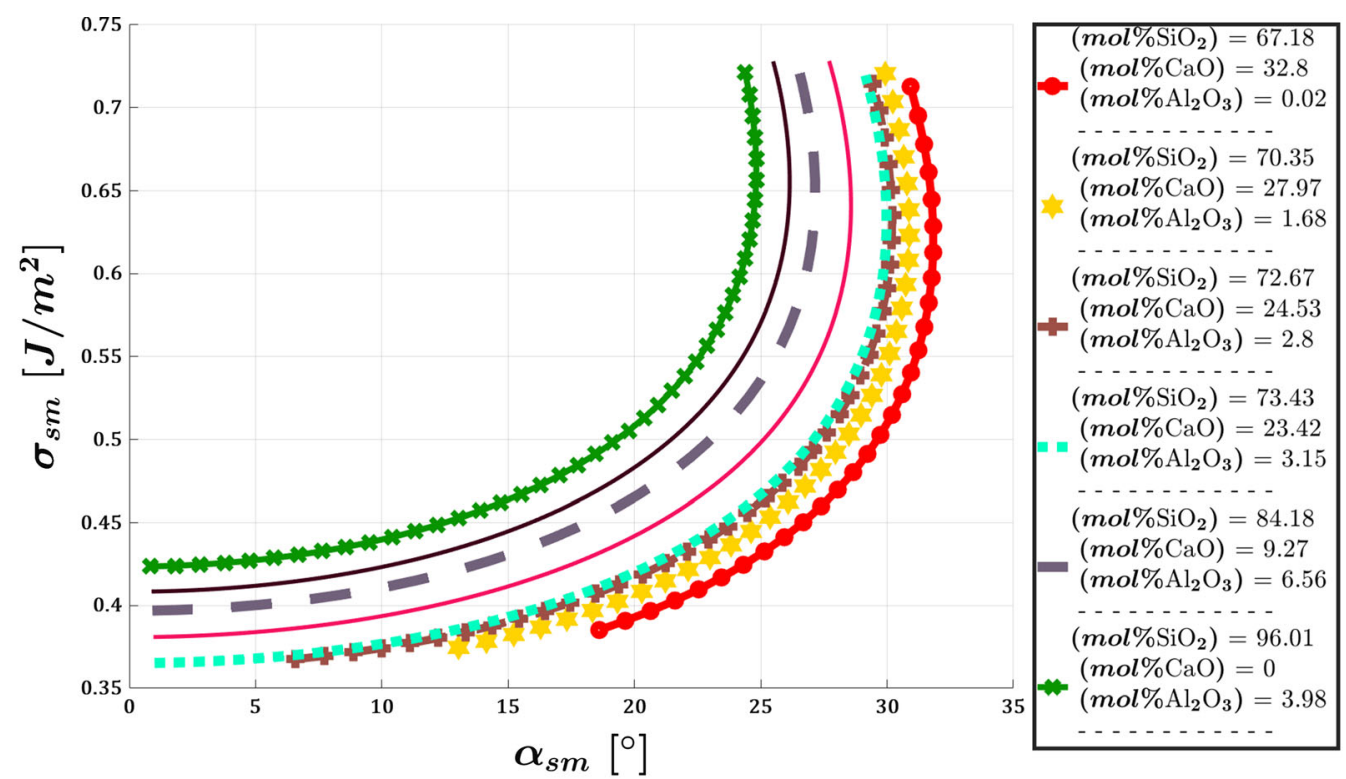

Fig. 12-Interfacial tension between slag and melt as a function of contact angle and bulk slag composition along the cristobalite/slag(liq) line. Similar procedure as Fig. 11, but $\sigma_{s g}$ is found from the model described in Section II-C and T=1873 K. $\sigma_{m g}$ was set equal to $0.73 \mathrm{~J} / \mathrm{m}^{2}$.

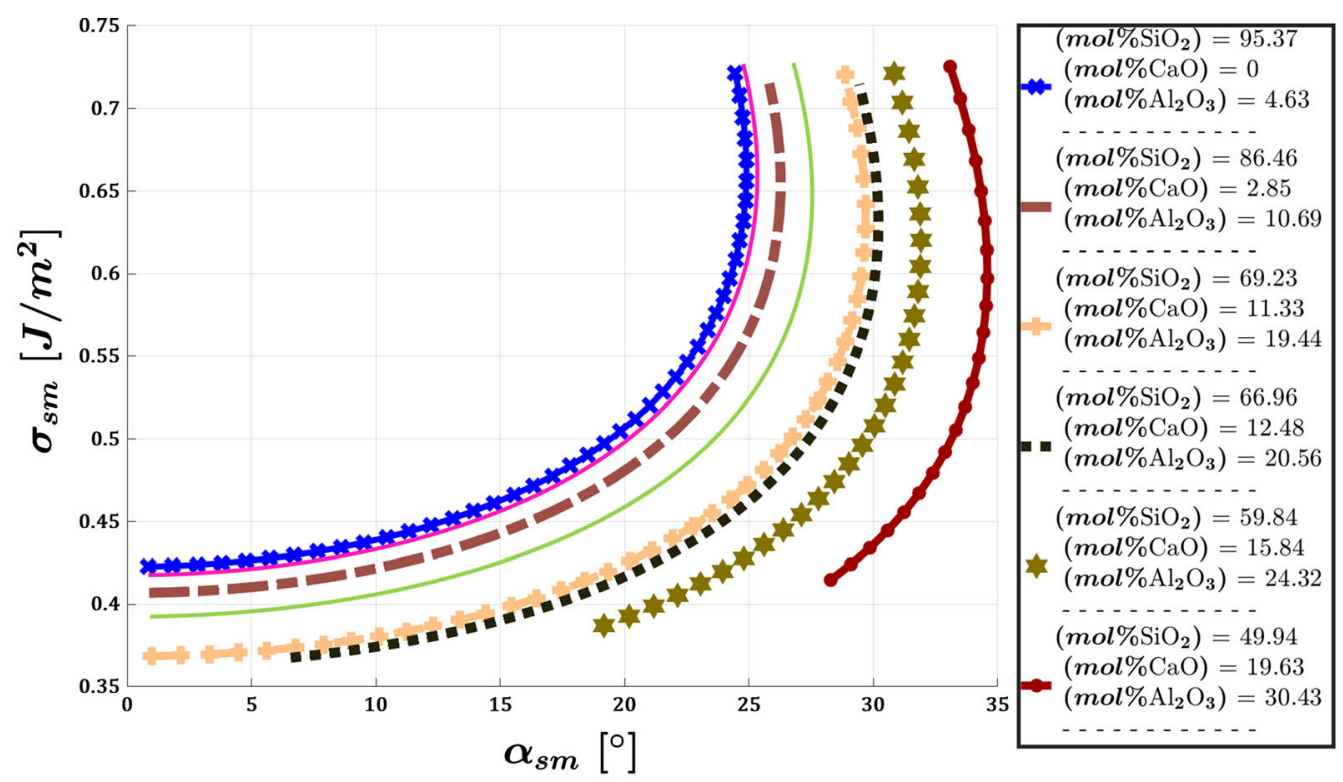

Fig. 13-Interfacial tension between slag and melt as a function of contact angle and bulk slag composition along the mullite/slag(liq) line. Similar procedure as Fig. 11, but $\sigma_{s g}$ is found from the model described in Section II-C and T=1873 K. $\sigma_{m g}$ was set equal to $0.73 \mathrm{~J} / \mathrm{m}^{2}$.

\section{E. Slag Droplet Geometry}

Much of this work has been dedicated to why it seems prudent to assume that the $\mathrm{SiO}_{2}-\mathrm{CaO}-\mathrm{Al}_{2} \mathrm{O}_{3}$ slag droplet can be assumed to have a "well defined" surface. This subsection concerns itself with what consequences this has for the slag droplet geometry as the slag concentration changes.

Equation 8 is but one of the ways to show how the different wetting angles $\left(\theta_{s}, \theta_{m}, \theta_{g}, \alpha_{s m}, \alpha_{s g}\right)$ and interfacial tensions $\left(\sigma_{s m}, \sigma_{s g}, \sigma_{m g}\right)$ in Figure $6(\mathrm{a})$ and 6(b) relate to each other, by the relationship between the sides and angles of a triangle. It can also be shown that for any value of the slag's primary wetting angle $\theta_{s}$, there will only be one valid solution for the secondary wetting angles between slag/melt $\alpha_{s m}$ and slag/gas $\alpha_{s g}$. A solution is only valid when every relationship is satisfied, and this can be found by plotting them against each other and identifying where they all intersect, as seen in Figure 11. If the same methodology is used as in Figure 11, but $\sigma_{s g} \approx \sigma_{s}$ is found from the model described in Section II-C, then the slag composition can also be added as a parameter. To our knowledge, there is no clear indication in the current literature that the surface 
structure of $\mathrm{SiO}_{2}-\mathrm{CaO}-\mathrm{Al}_{2} \mathrm{O}_{3}$ slag or liquid $\mathrm{Si}$, drastically changes when these two phases are in contact with each other, or when they are individually in contact with a gas containing oxygen for that matter. It thus seems reasonable to assume that the value of the interfacial tension between slag and melt lies in between the surface tension values of the slag and melt, $\sigma_{s}<\sigma_{s m}<\sigma_{m}$. If this is assumed then one gets Figures 12 and 13 .

The expression for the melt's surface tension $\sigma_{m}$, here assuming $\sigma_{m} \approx \sigma_{m g}$, in Table II by Shishkin and Basin 22 is not recommended for use above $1830 \mathrm{~K} . \sigma_{m}$ was here set as $0.73 \mathrm{~J} / \mathrm{m}^{2}$, as this value seems to be more in line with the data shown in their article at this temperature, than what their expression gives. The melt's surface tension was intentionally set toward the higher end of those shown in Shishkin and Basin, as the constricting effect, which will be discussed shortly, becomes more pronounced the lower $\sigma_{m}$ is.

Figures 12 and 13 show that increasing the amount of calcia and alumina in the slag causes the slag droplet to protrude further into the melt. The more a droplet protrudes into the metal melt, the faster it will start to get affected by the flow field, and thus it is likely that this should lead to the slag leaving the bubble faster, making room for new slag to form, and as such increase the refining rate. They also show that calcia will increase the contact angle more than alumina. As previously noted, calcia is critical for allowing alumina to attain its preferred structure in the slag, which when included with the previous points, makes the importance of calcia in the operation of OLR become quite apparent. Based on this, it becomes apparent that for smooth operation of OLR it is important to make sure that there always is enough calcium available to produce a slag which can efficiently extract dissolved aluminum in the melt, and provide a favorable slag droplet geometry. An important consequence of applying the constraint on the value of the slag/melt interfacial tension $\sigma_{s m}$, is that the possible valid values the wetting angle $\alpha_{s m}$ can take become smaller as the slag's silica concentration decreases. This means that even if there is currently not enough information available to solve the problem fully, it is still possible to make predictions of how the different parameters affect the slag droplet's geometry due to this constriction of possible solutions. It is also valuable to look at how the contact angle between the slag and gas changes, as can be seen in Figure 14. The most important observation from Figure 14 is that the possible solutions the wetting angle $\alpha_{s g}$ can take are constrained to steeper angles as the silica concentration decreases. Assuming a constant volume in the slag droplet, the contact area between the gas bubble and slag droplet will decrease as the droplet extends further into the melt. In turn, this strengthens the earlier statement that calcia is critical for the refining rate, as it should become easier for the slag droplet to detach from the gas bubble if its contact area becomes smaller. The overall model behavior does not change as long as $\sigma_{s} \leq \sigma_{s m} \leq \sigma_{m}$. Shishkin and Basin 22 have performed an extensive meta study on the surface tension of silicon $\sigma_{m}$. From their work it can be seen that there is quite a large variance in the literature values on the surface tension of silicon. What can be said is that $\sigma_{m} \in[0.68,0.8]\left[\mathrm{J} / \mathrm{m}^{2}\right], T=1800-1900 \mathrm{~K}$ is most likely the case. The range tested was $T=1773-1973 K$, as this is considered possible temperatures in OLR. As long as the slag's surface tension $\sigma_{s}$ is kept constant, decreasing the melt's surface tension $\sigma_{m}$ will cause the system to push toward steeper wetting angles between the slag and silicon melt $\alpha_{s m}$, while an increase favors shallow angles. Changing $\sigma_{s}$ will cause similar effects as it is the distance between $\sigma_{s}$ and $\sigma_{m}$ which dictates the behavior. Niu et al. 34, Yuan et al. 35, Hibiya et al. 36, and Shishkin and Basin 22 describe how dissolved oxygen in the melt [O] affects the melt surface tension $\sigma_{m}$ at different $T$. An

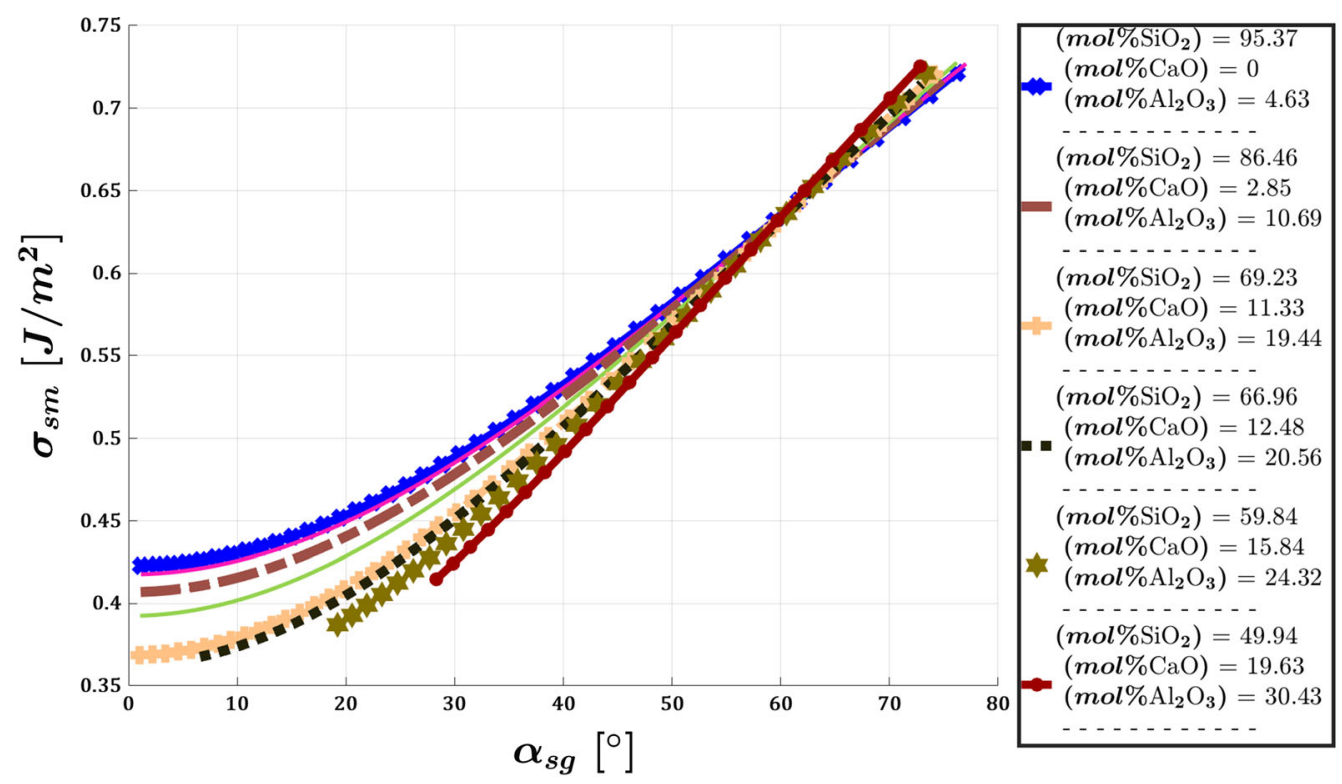

Fig. 14-Similar to Fig. 13, but the interfacial tension between slag and melt $\sigma_{s m}$ is now expressed as a function of the wetting angle between slag and gas $\alpha_{s g}$. 


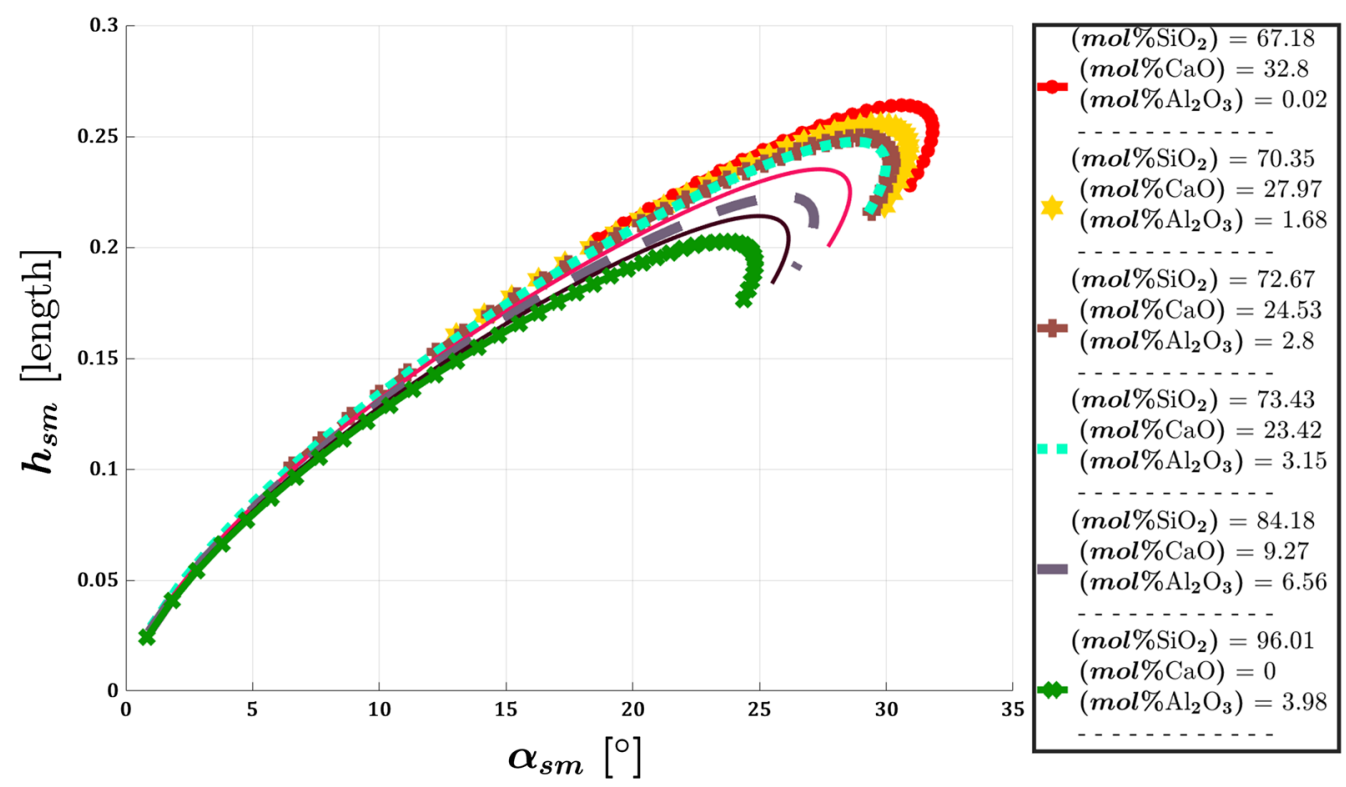

Fig. 15- Height of the slag droplet between the slag and melt $h_{s m}$ as a function of wetting angle between slag and melt $\alpha_{s m}$ and slag composition following the cristobalite/slag(liq) line. The slag droplet is assumed to have a constant volume of 1 with an arbitrary cubed length unit.

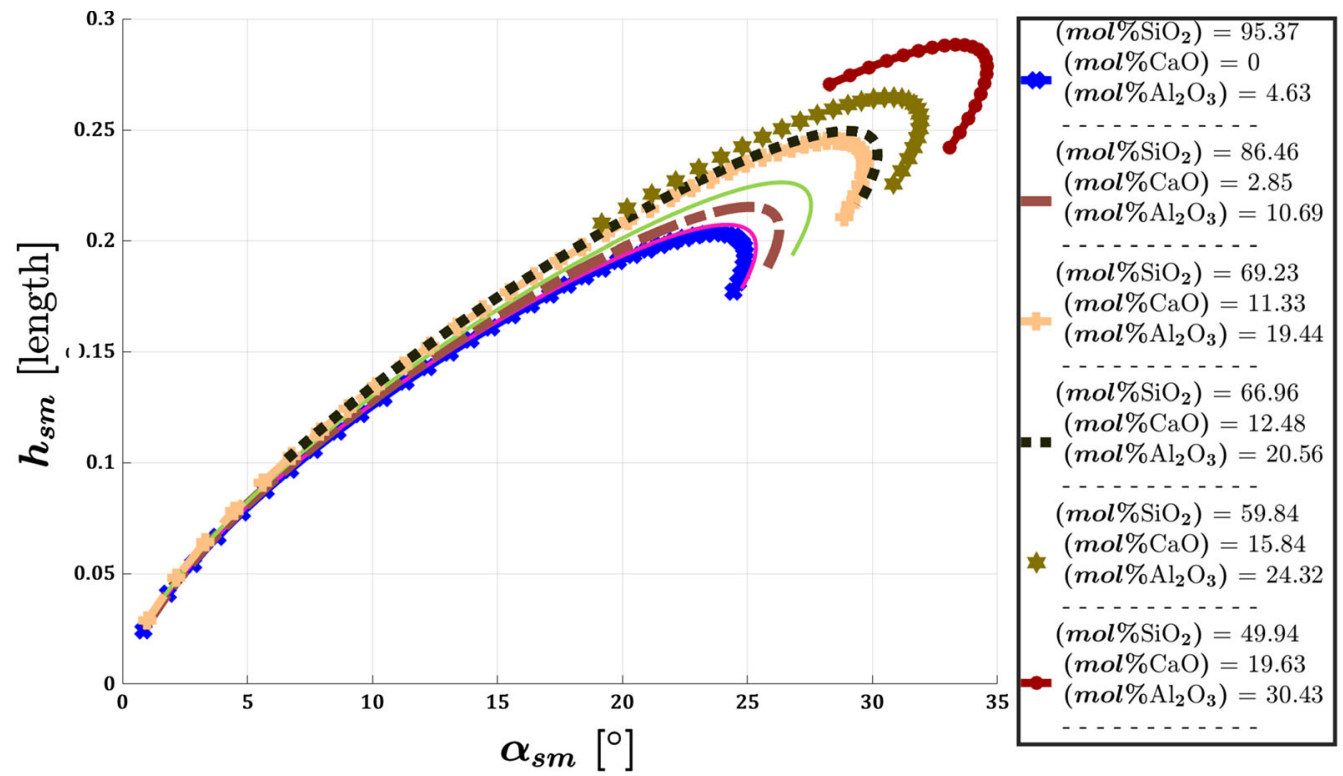

Fig. 16- Height of the slag droplet between the slag and melt $h_{s m}$ as a function of wetting angle between slag and melt $\alpha_{s m}$ and slag composition following the mullite/slag(liq) line. The slag droplet is assumed to have a constant volume of 1 with an arbitrary cubed length unit.

increase in the melt's dissolved oxygen concentration will result in a decrease in its surface tension $\sigma_{m}$, until the oxygen saturation limit $\omega_{[O], \text { sat }}$ is reached. Yuan et al. ${ }^{[35]}$ additionally presents experimental data on how silicon's surface tension $\sigma_{m}$ varies when molten silicon is subjected to an atmosphere where the oxygen partial pressure is higher than its saturation pressure $p_{\mathrm{O}_{2}}>p_{\mathrm{O}_{2} \text {,sat }}$, using argon as the bulk gas. As $p_{O_{2}}$ increases, $\sigma_{m}$ increases slightly, with some indications that it will flatten out. The authors write that this is most likely due to $\mathrm{SiO}_{2}$ formation on the surface, which can be seen from their samples. The drop in the melt's surface tension $\sigma_{m}$, seen in Yuan et al. 35, Niu et al. 34, and Hibiya et al. 36 is quite large, $\left.\quad \sigma_{m}(T) \approx 0.94 \sigma_{m}(T)\right|_{[O]_{s a t}} T=1693-1773 K$, approximately an 6 pct drop in $\sigma_{m}$ at full oxygen saturation is observed. For the slag it is assumed that as [Si] reacts with $\left\{\mathrm{O}_{2}\right\}$, the kinetics of $\left(\mathrm{SiO}_{2}\right)$ and $\{\mathrm{SiO}\}$ formation is fast, allowing close to local equilibrium between $\left(\mathrm{SiO}_{2}\right)$ and $\{\mathrm{SiO}\}$ at their contact surface. This is a reasonable assumption, since the slag droplet height is 


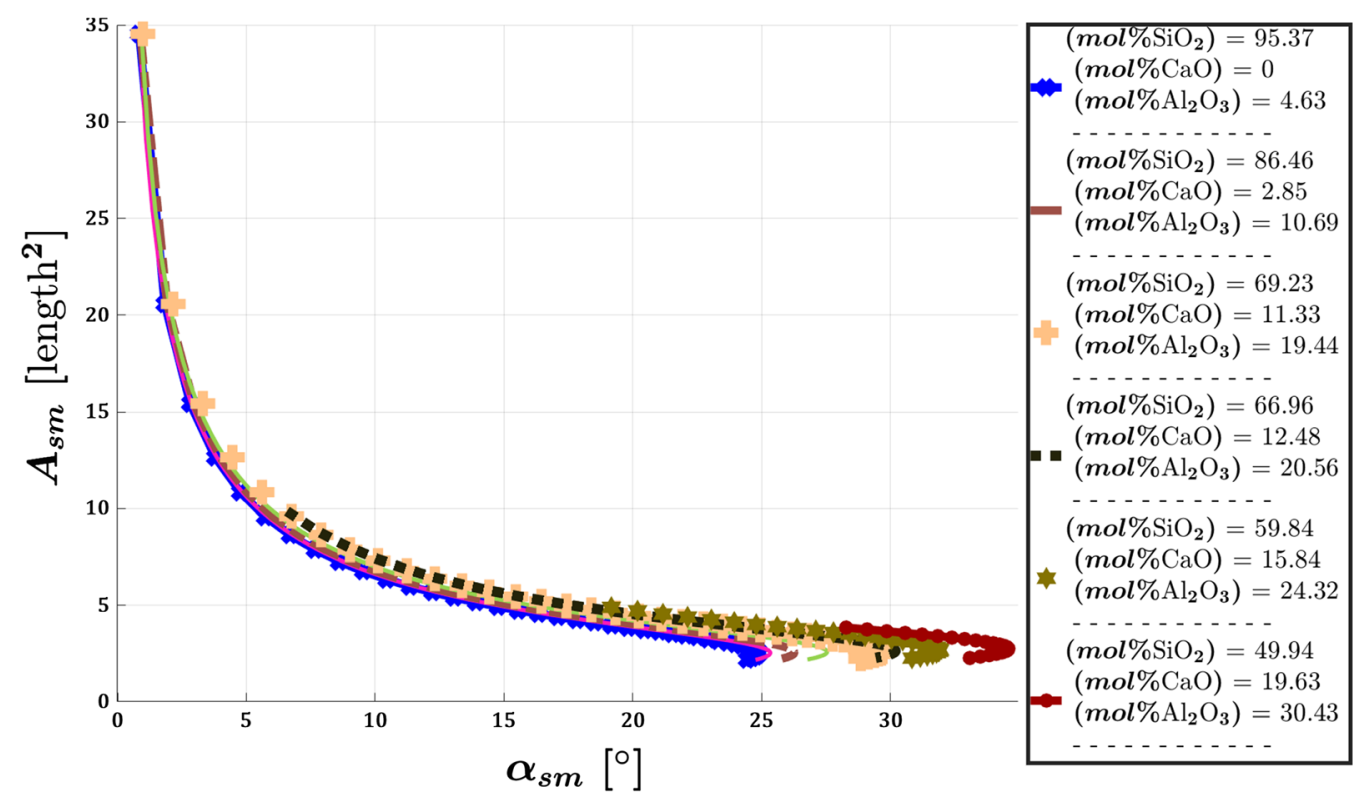

Fig. 17-Contact area between slag and melt $A_{s m}$ as a function of wetting angle between slag and melt $\alpha_{s m}$ along the mullite/slag(liq) line. The slag droplet is assumed to have a constant volume of 1 with an arbitrary cubed length unit.

quite small, and both reactions between $[\mathrm{Si}]$ and $\left\{\mathrm{O}_{2}\right\}$ occur close to the droplet. Both the slag and melt phase are in contact with the gas phase, so the primary change in interfacial tension should come from surface active species in the gas.

As [Ca] and [Al] react to form $\mathrm{Al}_{2} \mathrm{O}_{3}$ and $\mathrm{CaO}$ slag species, the equilibrium between the slag and $\{\mathrm{SiO}\}$ is altered. We have not found any literature concerning how $\sigma_{s}$ changes depending on $p_{\left\{O_{2}\right\}}$, at high $T$. Continuing from Figure 12 and 13 , if the droplet in question is assigned a constant volume $V_{\text {lens }}=1\left[\right.$ length $\left.{ }^{3}\right]$ (here "length" denotes an arbitrary length unit), the changes in contact area and height between the slag and melt $h_{s m}$, as a function of the wetting angle $\alpha_{s m}$ and slag composition can be calculated. This is shown in Figures 15,16 , and 17 , illustrating how the slag droplet protrudes into the melt.

Seen together, they provide a clearer picture of what occurs on the bubbles, which can be summed up as follows: Assuming a pure $\left(\mathrm{SiO}_{2}\right)$ nuclei is the initial slag state, the pure silica droplet $\left(\mathrm{SiO}_{2}\right)$ can exhibit very shallow wetting angles between the slag and melt $\alpha_{s m}$. This allows the silica droplet to spread out over the bubble surface, providing a large contact area between the slag and melt $A_{s m}$. As a result, even if diffusion is difficult, due to the high viscosity of $\mathrm{SiO}_{2}$, a high reaction rate between $\left(\mathrm{SiO}_{2}\right)$ and the impurities can still be attained. This is further facilitated by a low height between the slag and melt $h_{s m}$, which leads to a small diffusion length, previously noted in Section II-B. As the slag droplet grows it will react with [Ca] and [Al], increasing the concentration of $\left(\mathrm{Al}_{2} \mathrm{O}_{3}\right)$ and $(\mathrm{CaO})$, causing the droplet to contract radially, favoring steeper wetting angles between both the melt and gas.
Table III. Concentration of [Wt Pct Al] and [Wt Pct Ca] in the Unrefined Industrial Alloy Measured by Inductively Coupled Plasma Mass Spectroscopy (ICP-MS). The Sample Mean and Standard Deviation are Given in [Wt Pct], Based on a Set of 3 Sub-samples

\begin{tabular}{lcc}
\hline Impurity & Sample Mean & Sample Standard Deviation \\
\hline $\mathrm{Al}$ & 0.332 & 0.095 \\
$\mathrm{Ca}$ & 0.269 & 0.118 \\
\hline
\end{tabular}

This reduces the contact area between the slag and the gas bubble, while simultaneously causing the slag to protrude further into the melt, making it easier for whole/or parts of the droplet to get ripped off by the flow. It plausible that the slag droplet is not all detached at once, where only the part which protrudes into the melt itself gets swept away by the flow field. The part left behind will then start to grow again, continuing the cycle, but how plausible this is depends on many factors like slag viscosity and the flow field experienced by the extremities of slag droplet.

An industrial observation is that if the amount of dissolved calcium becomes too low, refining stops. This may be explained by how calcia dictates the behavior of alumina in the slag, which in turn dictates the slag geometry. Aluminosilicates do also have a very high viscosity, which should hamper diffusion, and such the reaction rate. Even though the droplet will have a large contact area with the melt it will still cling to the bubble surface, and with a high viscosity it can never get to the point where the droplet gets pulled off before the gas bubble leaves the melt. 


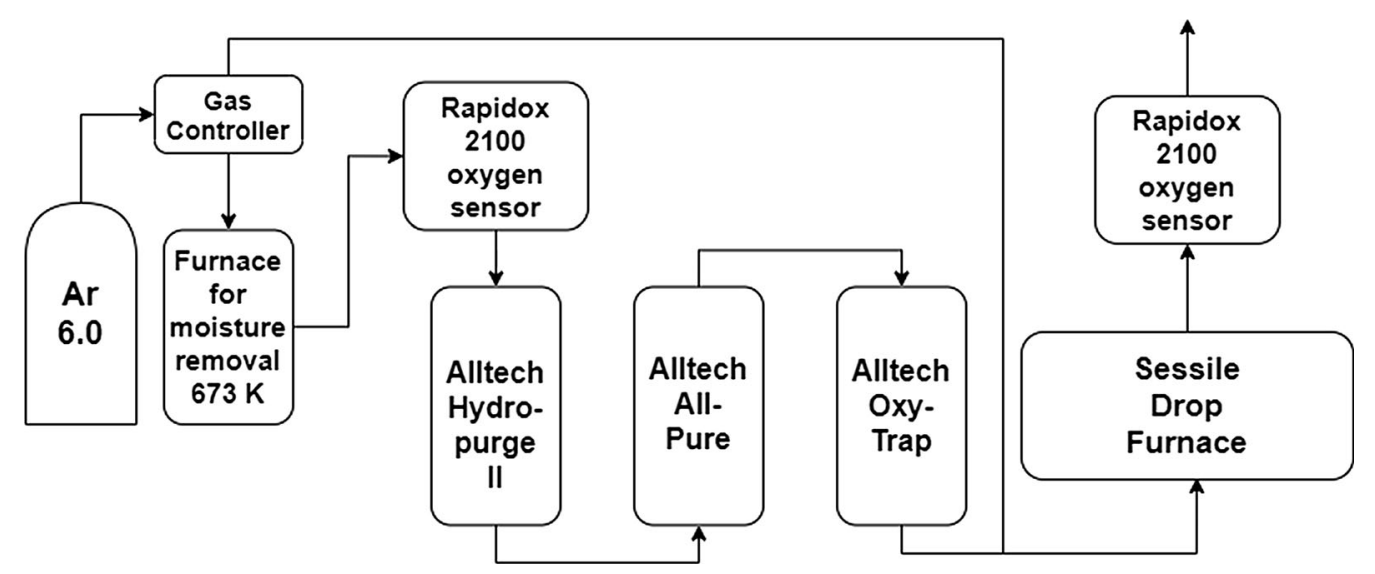

Fig. 18-Flowchart depicting the oxygen scrubbing system with the experimental setup.

\section{EXPERIMENTAL WORK}

As shown in the theoretical description, many of the predicted behavioral trends are not very sensitive to small changes in system properties. An example of this is the interfacial tension between the slag and melt, $\sigma_{s m}$, in Section II-E always behaves in a similar manner in the relevant temperature and slag concentration ranges. As a supplement to the theoretical description of slag nucleation and growth, the initial formation of $\mathrm{SiO}_{2}-\mathrm{Al}_{2} \mathrm{O}_{3}-\mathrm{CaO}$ slag from an industrial silicon alloy in contact with oxygen was investigated experimentally. The experiment was designed to explore the distribution of different oxides in the slag, as $\mathrm{SiO}_{2}$ is expected to be surface active while $\mathrm{Al}_{2} \mathrm{O}_{3}$ and $\mathrm{CaO}$ are not.

\section{A. Materials}

An approximately $1.5 \mathrm{~mm}$ cube was cut from an unrefined industrial alloy with composition listed in Table III. Afterwards the cube was cleaned with acetone and ethanol to remove any contamination from the cutting fluid, and left over night in a heating cabinet at $120^{\circ} \mathrm{C}$ to remove any excess moisture.

\section{B. Procedure}

The sample was placed on a ISO-88 graphite substrate in a sessile drop furnace under an $\operatorname{Ar} 6.0$ atmosphere (less than $1 \mathrm{ppmX}$ impurities), where the argon was first run through an oxygen scrubbing system. This oxygen scrubbing system consisted first of a graphite tube furnace at $673 \mathrm{~K}\left(400^{\circ} \mathrm{C}\right)$, which heated the gas and allows some of the moisture to escape and condense before the gas is fed through an Alltech Hydropurge II moisture trap. Since Ar 6.0 was used, this step was arguably redundant, as the initial amount of moisture in the gas (less than $0.5 \mathrm{ppmX}^{[37]}$ ) should not be sufficient to exceed the moisture taps capacity. Next, the gas is fed through Alltech's ALL-Pure ${ }^{\mathrm{TM}}$ Nitrogen Purifier and Oxy-Trap module. The ALL-Pure ${ }^{\mathrm{TM}}$ gas purifier is a multi-purification system which contains an oxygen, moisture, and hydrocarbon purification module, where the Oxy-Trap further reduces the oxygen concentration.
A partial pressures less than $10^{-16}$ bar $\mathrm{O}_{2}$ was measured with a Rapidox 2100 oxygen sensor placed at the furnace gas outlet. The experimental setup is shown in Figure 18. Figure 8 predicts that if the oxygen activity in the gas is less than $3.90 \cdot 10^{-5}$ then no new slag will form. Even though activities of gaseous species and their partial pressures are not necessarily equal, the difference in this case is considered so large that it can safely be assumed that the oxygen partial pressure in the furnace is too low to form slag nuclei. Formation of $\{\mathrm{SiO}\}$ was not considered, as any amount produced would be small and swept away by the argon flow. The furnace is then heated to $1873 \mathrm{~K}\left(1600^{\circ} \mathrm{C}\right)$ over 20 minutes, and held there for $15 \mathrm{~min}$. After spending $5 \mathrm{~min}$ at $1873 \mathrm{~K}$ $\left(1600^{\circ} \mathrm{C}\right)$ the sample was exposed to $1 \mathrm{~min}$ of un-scrubbed $\mathrm{Ar}$ 6.0, to provide enough oxygen to promote slag formation. After $15 \mathrm{~min}$ at $1873 \mathrm{~K}$ the furnace was turned off, and the sample was subjected to rapid cooling to room temperature. The sample was then stored in an desiccator and sent for imaging. Light surface cleaning with one drop of acetone and ethanol, with heating the sample to remove moisture, were performed right before the imaging started.

\section{Imaging and Analysis of Reacted Samples}

The surface of the sample was then imaged in a scanning electron microscope (SEM), and a small cross-section was selected and extracted with a focused ion beam emitter (FIB). Since the silicon alloy was saturated with carbon, first from the industrial process and later from the substrate, there was large patches of $\mathrm{SiC}$ on the silicon surface. From the SEM images it was documented that slag was present on the surface of both the metal and SiC phase, shown in Figure 19(b). A cross-section was therefore selected such, that it covered both the silicon and $\mathrm{SiC}$ phases, as the $\mathrm{SiC}$ phase is very distinct, making it easier to distinguish where the $\mathrm{SiC}$ phase ends and the slag phase begins than between the slag and $\mathrm{Si}$. The selected cross-section was covered with a layer of carbon and gallium to protect the surface during further handling, seen outlined in blue in Figure 19(a). A FEI Helios G4 FIB emitting gallium 


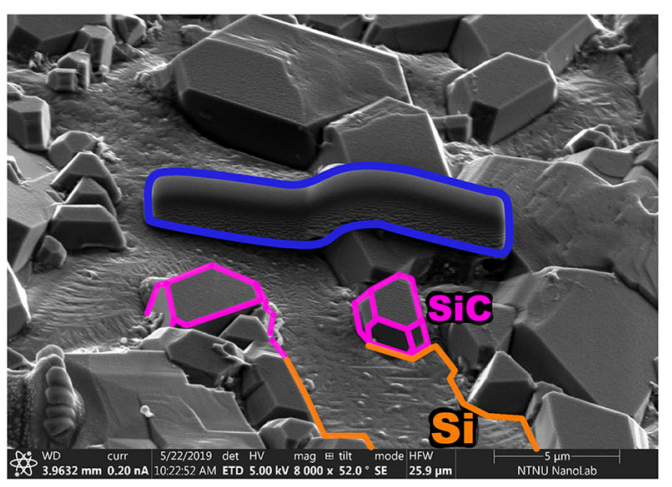

(a)

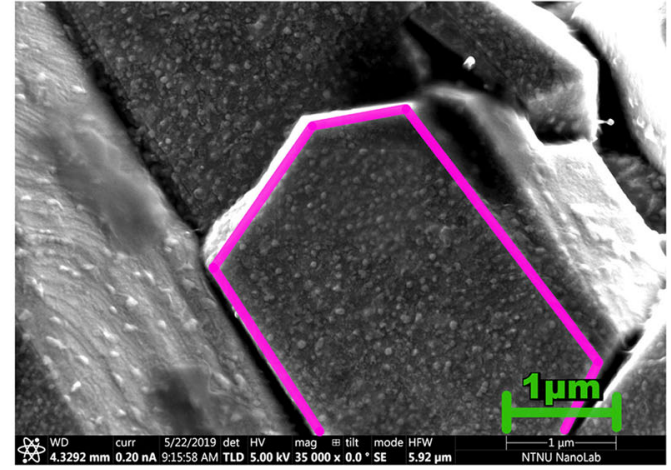

(b)

Fig. 19-(a) SEM image of the silicon surface. SiC crystals outlined in pink and Si phase outlined in orange. Selected cross-section is covered by a protective layer of carbon and gallium, outlined in blue. (b) SEM image of a SiC face outlined in pink. The rough surface texture indicates that there is another phase, here slag, on top of the SiC surface.

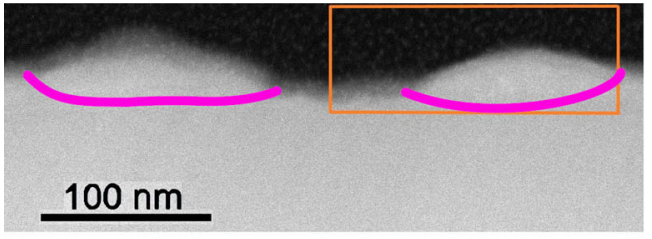

(a)

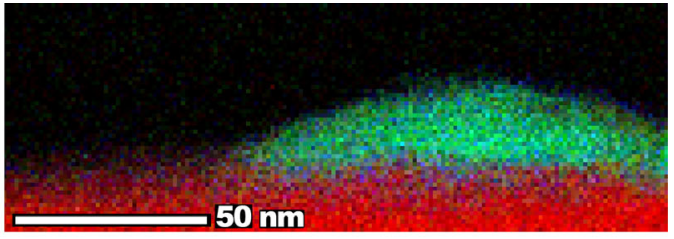

(b)

Fig. 20 - (a) STEM image of two slag droplets on the SiC surface. Pink lines indicate the SiC/slag interface. (b) RGB concentration map of the area inside the orange box in a). $\mathrm{Si}$ (EELS) is red, $\mathrm{Al}(\mathrm{EELS})$ is green, and Blue is $\mathrm{Ca}(\mathrm{EDS})$.

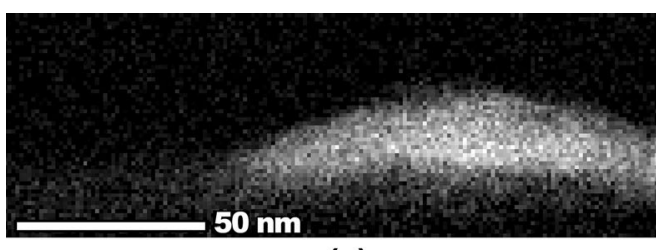

(a)

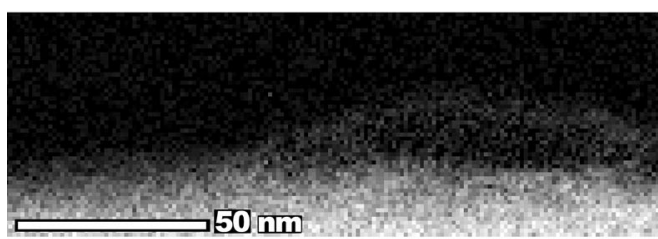

(c)

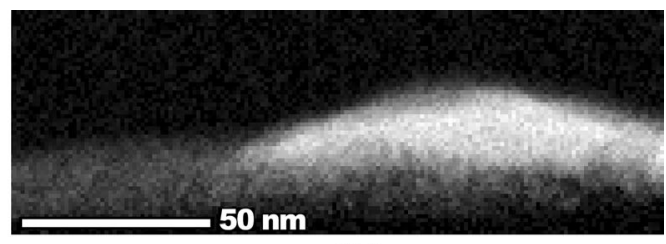

(b)

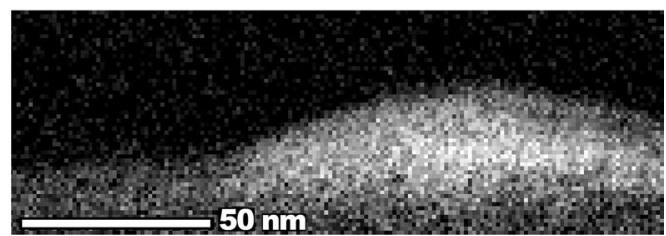

(d)

Fig. 21-EELS maps of (a) aluminum, (b) oxygen, $(c)$ silicon, and $(d)$ calcium.

ions, was used to extract and thin the sample to electron transparency (approx. $200 \mathrm{~nm}$ ). TEM/STEM (scanning transmission electron microscopy) imaging and chemical mapping was performed with a probe/image aberration-corrected JEOL ARM-200F cold field emission gun microscope, operated at $200 \mathrm{kV}$. In STEM, the probe current was approximately $300 \mathrm{pA}$ with a convergence angle of $27 \mathrm{mrad}$ and collection angles between 67-118 mrad. Electron energy loss spectroscopy (EELS) was collected simultaneously with the energy-dispersive X-ray spectra (EDS). EELS was run using a GIF
Quantum with a dispersion of $1 \mathrm{eV}$, collection angle of $67 \mathrm{mrad}$, with a $20 \mathrm{~ms}$ dwell time, while EDS was conducted using a JEOL Centuro detector.

\section{Results}

On the SiC surface, small spherical cap shaped slag droplets were imaged, shown in Figure 20(a). The leftmost droplet was not fully cut through, so chemical mapping is only provided for the rightmost droplet, where Figure 20(b) shows an RGB map of said slag 


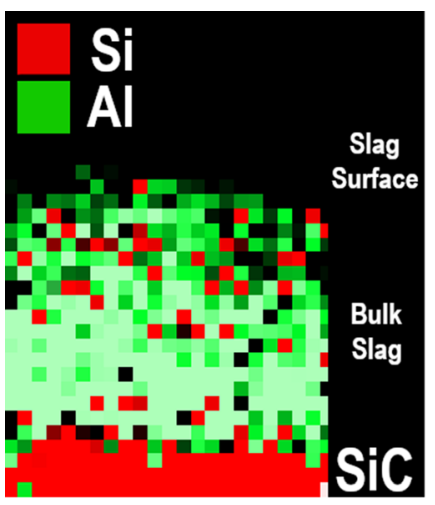

(a)

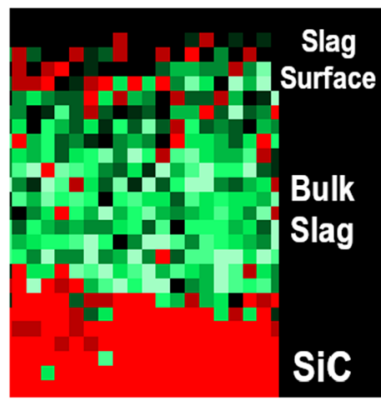

(b)
Fig. 22-(a) EELS map retaining only the strongest concentration signal for $\mathrm{Al}($ Green) and $\mathrm{Si}(\mathrm{Red})$ in the middle portion of the slag droplet in Fig. 21. The sidebar shows where the slag surface, center, and $\mathrm{SiC}$ are located. (b) EDS map of the same area as in (a). $\mathrm{Al}$ is colored in green and $\mathrm{Si}$ in red.

droplet. Figure 21(a) and 21(b) shows the individual concentration maps of $\mathrm{Al}$ and $\mathrm{O}$ respectively. Comparisons of the strongest signals from $\mathrm{Si}$ and $\mathrm{Al}$ can be found in Figures 22(a) and 22(b), extracted from the EELS and EDS maps of the elements respectively. These figures were generated by greatly increasing the contrast in Figure 21(a) and 21(c), and their EDS counterparts not shown here, retaining only the strongest signals from each element. The silicon map was then superimposed on the aluminum map in each case, resulting in Figures 22(a) and 22(b).

Figure 22(a) displays the middle portion of the slag droplet, where a brighter color represents a higher concentration of each species, and the color pallet of the EELS maps of aluminum and silicon, Figures 21(a) and 21(c), have been changed to green and red respectively. In the case of aluminum, Figure 22(a) shows its highest concentration at the center of the slag droplet, indicated by the light green color, and that it decreases toward the slag surface, as it transitions toward darker shades of green. Silicon, displayed in red, has a weaker EELS signal in the slag than $\mathrm{Al}$, seen by comparing Figures 21(c) and 21(a). When the strongest silicon signal in the slag droplet is extracted, one gets the red parts of Figure 22(a). Here, the strongest silicon signal in the slag is at the slag surface, as there are more red squares at the slag surface than in the bulk. The same behavior is also found in the EDS map, if it is subjected to a similar treatment as Figure 20(a), shown in Figure 22(b).

\section{E. Discussion of the Experimental Work}

Figures 22(a) and 22(b) support the theoretical claims that silica is surface active while alumina is not. By comparing the different concentration maps in Figure 21, it is expected that $\mathrm{Ca}$ has a concentration profile close to that of $\mathrm{Al}$ in the slag. The high amount of noise present in Figure 21(d) makes it unsuitable for the same type of image manipulation used to create Figures 22(a) and 22(b), so it was omitted. Primarily EELS, and less so EDS, has some difficulties distinguishing between $\mathrm{Ca}$ and $\mathrm{C}$, due to their energy peaks being close together, which is the reason why $\mathrm{SiC}$ seemingly contains $\mathrm{Ca}$ in Figures 20(b) and 21(d). However, the rest of the elements have energy peaks so far apart that one can clearly distinguish between them. While the elements can be easily distinguished from each other, there would seem to be very little silicon in the slag, as seen in Figure 21(c). This is assumed to be a result of the imaging method used. It is thought that the silicon signal emitted by the $\mathrm{SiC}$ is so much stronger than that from the slag, overshadowing the silicon signal from the slag. This is a known problem which might occur when using EELS and EDS in TEM, as these analysis methods are better suited for finding which elements are present rather than quantifying them. The concentration maps in Figure 21 are thus useful for comparing the relative spatial concentration of each element, but should not be used to compare absolute concentration of different elements.

\section{SUMMARY AND CONCLUSIONS}

The results and conclusions of the theoretical and experimental work in this study can be summarized as follows:

1) This work presents a theoretical framework, which expresses nucleation and growth of $\mathrm{SiO}_{2}-\mathrm{CaO}-\mathrm{Al}_{2} \mathrm{O}_{3}$ slag droplets on oxygen-rich gas bubbles related to refining of MG-Si, using classical macroscale thermodynamics.

The theoretical framework describes how nanoscale processes like slag nucleation and its initial growth, can be expressed using classical macroscale thermodynamics, and forms a foundation for modeling refining of $\mathrm{MG}-\mathrm{Si}$.

2) The low surface tension and high surface activity of silica is the key which allows nucleation and growth of $\mathrm{SiO}_{2}-\mathrm{CaO}-\mathrm{Al}_{2} \mathrm{O}_{3}$ slag droplets to be described using classical macroscale thermodynamics.

Silica's strong surface structure, represented by its low surface tension, makes it a special case, where the surface can be considered as "well defined", even when a silica nuclei consists of a small number of molecules. That the surface can be considered "well defined" is essential, as this is generally what classical macroscale thermodynamics sees as a surface, and fundamentally will not work without it. Since silica is highly surface active, the theoretical framework states that the surface will always be "well defined" as long as silica defines the surface. Thus, as long as the concentrations of calcia and alumina are low during the slag droplet's initial growth stage (until the number of particles in the slag exceed 1000), it is assumed to retain its "well defined" surface. Above 
this, classical macroscale thermodynamics is considered to be generally applicable. How accurate the assumption that the slag droplet retains its "well defined" surface is currently not known, but a high nucleation rate and low availability of impurity elements compared to silicon to form the slag, favors this assumption.

3) The framework may be used to predict the viability of refining for different melt compositions and bubble oxygen concentrations, resulting from different slag droplet composition, droplet geometries and properties at different spatial regimes. This also allows calculation and/or verification of refining parameters which are difficult to find experimentally.

A key feature of the proposed theoretical framework is that it provides a framework for describing the slag droplet as it grows between different spatial regimes which is continuous. By being continuous, all properties relating to the slag growth are linked together regardless of which spatial regime they are measured in, and they can be expressed by the same classical macroscale thermodynamics. This allows for instance experimental results on the solubility of oxygen in molten silicon at different oxygen partial pressures, to be more easily implemented into industrial refining models, thus shortening the path between academic research and its industrial application. Another example, is that macroscale experiments can be used to provide information about nanoscale phenomena, where the macroscale experiments are often much less resource intensive and more readily available.

4) The model framework predicts, in accordance with industrial observations, that the concentration of $\mathrm{Ca}$ in the $\mathrm{Si}$ melt and oxygen concentration in the gas bubbles are important parameters for the effectiveness of the Si refining process. It has also been shown experimentally that there are strong indications that silica is surface active, and that alumina is not surface active in $\mathrm{SiO}_{2}-\mathrm{CaO}-\mathrm{Al}_{2} \mathrm{O}_{3}$ slag.

\section{FUTURE WORK}

In on-going work, the reaction kinetics between air/ Ar gas and Si-alloys of different composition is explored experimentally. An iterative thermodynamic modeling approach is used to expand the slag formation framework into a model able to predict the refining behavior in industrial vessels. In the future we would also like to use the proposed framework to estimate the interfacial tension between silicon and $\mathrm{SiO}_{2}-\mathrm{CaO}-\mathrm{Al}_{2} \mathrm{O}_{3}$ slags experimentally. The framework expresses the interfacial tension as a function of multiple individually measurable parameters, this makes it possible to create experimental setups where multiple parameters are measured at once, to attain the necessary statistical.

\section{ACKNOWLEDGMENTS}

This publication has been funded by the SFI Metal Production, (Centre for Research-based Innovation, 237738). The authors gratefully acknowledge the financial support from the Research Council of Norway and the partners of the SFI Metal Production. The Research Council of Norway is acknowledged for the support to the Norwegian Micro- and Nano-Fabrication Facility, NorFab, project number 295864/F50.

\section{CONFLICT OF INTEREST}

The authors declare that they have no conflict of interest.

\section{OPEN ACCESS}

This article is licensed under a Creative Commons Attribution 4.0 International License, which permits use, sharing, adaptation, distribution and reproduction in any medium or format, as long as you give appropriate credit to the original author(s) and the source, provide a link to the Creative Commons licence, and indicate if changes were made. The images or other third party material in this article are included in the article's Creative Commons licence, unless indicated otherwise in a credit line to the material. If material is not included in the article's Creative Commons licence and your intended use is not permitted by statutory regulation or exceeds the permitted use, you will need to obtain permission directly from the copyright holder. To view a copy of this licence, visit http://creativec ommons.org/licenses/by/4.0/.

\section{FUNDING}

Open access funding provided by NTNU Norwegian University of Science and Technology (incl St. Olavs Hospital - Trondheim University Hospital).

\section{LIST OF SYMBOLS}

\section{SPECIES PHASE LOCATION}

[El] Species El is in the alloy phase

(El) Species El is in the slag phase

$\{\mathrm{El}\}$ Species $\mathrm{El}$ is in the gas phase

\section{LATIN SCRIPT}

$\mathrm{A}_{s} \quad$ Surf. area $\left[\mathrm{m}^{2}\right]$

$\bar{A}_{i} \quad$ Surf. molar coverage $\left[\mathrm{m}^{2} / \mathrm{mol}\right]$

a Activity [-] 
Ref. Dissolved [1 wt pct]Gaseous [1 bar]Pure sol/liq [100 mol pct]

c Dimensionless wt pct [wt pct/1 wt pct]

d Diameter [m]

$\bar{d}_{0} \quad$ Init. Sauter d [m]

$\mathrm{H}$ Height [m]

$\mathrm{h}$ Droplet height [m]

m Mass [kg]

n Moles [mol]

$\mathrm{n}^{\star} \quad$ Critical $\mathrm{n} \quad[\mathrm{mol}]$

$\mathrm{P} \quad$ Total pressure [Pa], [bar]

p Partial pressure [Pa], [bar]

$\mathrm{R}$ Gas constant $[\mathrm{J} /(\mathrm{molK})]$

$\mathrm{r}_{G} \quad$ Droplet radius [m]

$\mathrm{r}_{G}^{\star} \quad$ Critical $\mathrm{rG} \quad[\mathrm{m}]$

$\mathrm{T}$ Temperature $[\mathrm{K}],\left[{ }^{\circ} \mathrm{C}\right]$

$\mathrm{V}$ Volume $\left[\mathrm{m}^{3}\right]$

$\mathrm{V}_{m} \quad$ Molar volume $\left[\mathrm{m}^{3} / \mathrm{mol}\right]$

$\mathrm{X}$ Mole fraction [-]

$\mathrm{X}$ Distance [m]

\section{GREEK SCRIPT}

$\begin{array}{ll}\alpha & \text { Contact angle }\left[{ }^{\circ}, \mathrm{rad}\right] \\ \Delta & \text { Differential }[-] \\ \Delta \mu & \text { Chemical potential }[\mathrm{J} / \mathrm{mol}] \\ \omega & \text { Mass fraction }[-] \\ \rho & \text { Density }\left[\mathrm{kg} / \mathrm{m}^{3}\right] \\ \varrho & \text { Particle density }\left[\mathrm{particles} / \mathrm{m}^{3}\right] \\ \sigma_{i} & \text { Surface tension }\left[\mathrm{J} / \mathrm{m}^{2}\right] \\ \sigma_{i j} & \text { Interfacial tension }\left[\mathrm{J} / \mathrm{m}^{2}\right] \\ \varsigma_{p} & \text { Particle amount } \\ \varsigma & \text { Critical particle amount } \\ \theta & \text { Contact angle }\left[{ }^{\circ}, \mathrm{rad}\right]\end{array}$

\section{SUBSCRIPTS}

$\begin{array}{ll}\mathrm{g} & \text { Gas } \\ \mathrm{s} & \text { Slag } \\ \mathrm{m} & \text { Alloy melt } \\ \mathrm{b} & \text { Bubble } \\ \text { sat } & \text { Saturated }\end{array}$

lens The whole lens

\section{SUPERSCRIPT}

b Bulk

s Surface

\section{ABBREVIATIONS}
MG-Si Metallurgical grade $\mathrm{Si}$
OLR Oxidative ladle refining

\section{REFERENCES}

1. I. Kero, M.K. Næss, V. Andersen, and G.M. Tranell: Metall. Mater. Trans. B, 2015, vol. 46, pp. 1186-94.

2. G.K. Sigworth: Can. Metall. Q., 2020, vol. 59, pp. 251-61.

3. A. Schei, J.K. Tauset, and H. Tveit: Production of High Silicon Alloys, 1st ed., Trondheim, Tapir Forlag, 1998, pp. 233-73.

4. J. E. Olsen, D. Darmana, A. Ashrafian, K. Tang, 6th International Conference on CFD in Oil \& Gas and Metallurgical and Process Industries, Trondheim, Norway, Conference Proceedings, 2008.

5. A. Ashrafian, S.T. Johansen, S. Gaal, B. Andresen, 6th International Conference on CFD in Oil \& Gas and Metallurgical and Process Industries, Trondheim, Norway, Conference Proceedings, 2008.

6. P.H. Calderbank: Trans. Inst. Chem. Eng, 1958, vol. 36, pp. $433-$ 40.

7. K. Tang, Report No. F8532, SINTEF Materials and Chemistry, Trondheim, (2007).

8. M. J. Assael, I. J. Armyra, J. Brillo, S.V. Stankus, J. Wu, W.A. Wakeham. J. Phys. Chem. Ref. Data. 2012. vol. 41, pp. 033101-1 to $033101-16$.

9. J.W. Gibbs. Trans. Conn. Acad. Arts Sci. 1874, vol. 3, https://arch ive.org/details/Onequilibriumhe00Gibb, Accessed (27 June 2017).

10. J.W. Gibbs. Trans. Conn. Acad. Arts Sci., 1877, vol. 3, https://a rchive.org/details/Onequilibriumhe00GibbA, Accessed (27 June 2017).

11. D. Kashchiev: Nucleation, 1st ed., Butterworth-Heinemann, Oxford, 2000, pp. 9-112.

12. I.V. Kalikmanov: Nucleation Theory, 1st ed., Springer, Dordrecht, 2013, pp. 55-70

13. S.M. Thompson, K.E. Gubbins, J.P.R.B. Walton, R.A.R. Chantry, and J.S. Rowlinson: J. Chem. Phys, 1984, vol. 81, pp. 530-42.

14. I.V. Schweigert, K.E.J. Lehtinen, M.J. Carrier, M.R. Zachariah: Phys. Rev. B, vol. 65, pp. 235410-1 to 235410-9 (2002).

15. A. Roder, W. Kob, and K. Binder: J. Chem. Phys, 2001, vol. 114, pp. 7602-14.

16. G. Vaccaro, G. Buscarino, S. Agnello, A. Sporea, C. Oproiu, D.G. Sporea, and F.M. Gelardi: J. Phys. Chem. C, 2012, vol. 116, pp. 144-49.

17. P.G. De Gennes, F. Brochard-Wyart, D. Quéré. Capillarity and Wetting Phenomena, Translation of 1st ed. to English by A. Reisinger, Springer Science \& Business Media, New York, 2004, pp. 54-56.

18. M.K.Næss, IMA NTNU. Mechanisms and Kinetics of Liquid Silicon Oxidation, PhD. Thesis, Trondheim, (2013).

19. K.C. Mills and B.J. Keene: Int. Mater. Rev., 1987, vol. 32, pp. 1120.

20. T. Narushima, K. Matsuzawa, Y. Mukai, Y. Iguchi: Mater. Trans. JIM, vol. 35, pp. 522-28 (1994).

21. T. Tanaka, K. Hack, T. Iida, and S. Hara: Z. Metallkd., 1996, vol. 87 , pp. $380-89$

22. A.V. Shishkin and A.S. Basin: Theor. Found. Chem. Eng., 2004, vol. 38 , pp. $660-68$

23. Y. Waseda, J.M. Toguri. The Structure and Properties of Oxide Melts, 1st ed., World Scientific Publishing Co. Pte. Ltd., pp. 5-7 (1998).

24. J.O'M. Bockris, J.D. Mackenzie, J.A. Kitchener. Trans. Faraday Soc. 1955 , vol. 51 , pp. $1734-47$.

25. F.D. Richardson: Physical Chemistry of Melts in Metallurgy, 1st ed., Academic Press, Cambridge, 1974, pp. 92-99.

26. T. Tanaka: Miner. Process. Extr. Metall., 2011, vol. 120, pp. 22934.

27. M. Nakamoto, T. Tanaka, L. Holappa, and M. Hämäläinen: ISIJ Int., 2007, vol. 47, pp. 211-16.

28. M. Nakamoto, A. Kiyose, T. Tanaka, L. Holappa, and M. Hämäläinen: ISIJ Int., 2007, vol. 47, pp. 38-43.

29. T. Fabritius, J. Riipi, M. Järvinen, O. Mattila, E.-P. Heikkinen, A. Kärnä, J. Kurikkala, P. Sulasalmi, and J. Härkki: ISIJ Int., 2010, vol. 50, pp. 797-803. 
30. M. Hanao, T. Tanaka, M. Kawamoto, and K. Takatani: ISIJ Int., 2007, vol. 47, pp. 935-39.

31. N.A. Arutyunyan, A.I. Zaitsev, and N.G. Shaposhnikov: Russ. J. Phys. Chem. A, 2010, vol. 84, pp. 7-12.

32. B.J. Keen: Slag Atlas Part 10, 2nd ed., Verlag Stahleisen GmbH, Dusseldorf, 1995, p. 430.

33. S.T. Bromley, M.A. Zwijnenburg, Th. Maschmeyer. Phys. Rev. Lett., vol. 90, pp. 035502 1-4 (2003).

34. Z. Niu, K. Mukai, Y. Shiraishi, T. Hibiya, K. Kakimoto, and M. Koyama: J. Jpn. Assoc. Cryst. Growth., 1997, vol. 24, pp. 369-78.
35. Z.F. Yuan, K. Mukai, and W.L. Huang: Langmuir, 2002, vol. 18, pp. 2054-62.

36. T. Hibiya, S. Nakamura, K. Mukai, Z.-G. Niu, N. Imaishi, S.-I. Nishizawa, S.-I. Yoda, M. Koyama. Philos. Trans. R. Soc. A vol. 356, pp. 899-909 (1998).

37. Linde AG. Promotional Datasheet: HiQ ${ }^{\circledR}$ Specialty Gases Finder Argon. Accessed 04 Aug 2020.

Publisher's Note Springer Nature remains neutral with regard to jurisdictional claims in published maps and institutional affiliations. 